\title{
Coupling Poisson rectangular pulse and multiplicative microcanonical random cascade models to generate sub-daily precipitation timeseries
}

\author{
Ina Pohle ${ }^{\mathrm{a}, \mathrm{b}, *}$, Michael Niebisch ${ }^{\mathrm{a}}$, Hannes Müller ${ }^{\mathrm{c}}$, Sabine Schümberg ${ }^{\mathrm{a}}$, \\ Tingting Zha ${ }^{\mathrm{a}}$, Thomas Maurer ${ }^{\mathrm{a}}$, Christoph Hinz ${ }^{\mathrm{a}}$ \\ ${ }^{a}$ Chair of Hydrology and Water Resources Management, Brandenburg University of \\ Technology Cottbus-Senftenberg, Siemens-Halske-Ring 8, 03046, Cottbus, Germany \\ ${ }^{b}$ Environmental and Biochemical Sciences, The James Hutton Institute, Craigiebuckler, \\ AB158QH, Aberdeen, UK \\ ${ }^{c}$ Institute of Hydrology and Water Resources Management, Leibniz Universität \\ Hannover, Appelstraße 9a, 30167, Hanover, Germany
}

\begin{abstract}
To simulate the impacts of within-storm rainfall variabilities on fast hydrological processes, long precipitation time series with high temporal resolution are required. Due to limited availability of observed data such time series are typically obtained from stochastic models. However, most existing rainfall models are limited in their ability to conserve rainfall event statistics which are relevant for hydrological processes. Poisson rectangular pulse models are widely applied to generate long time series of alternating precipitation events durations and mean intensities as well as interstorm period durations. Multiplicative microcanonical random cascade (MRC) models are used to disaggregate precipitation time series from coarse to fine temporal
\end{abstract}

\footnotetext{
*Corresponding author

Email address: Ina.Pohle@b-tu.de, Ina.Pohle@hutton.ac.uk (Ina Pohle)
} 
resolution.

To overcome the inconsistencies between the temporal structure of the Poisson rectangular pulse model and the MRC model, we developed a new coupling approach by introducing two modifications to the MRC model. These modifications comprise (a) a modified cascade model ("constrained cascade") which preserves the event durations generated by the Poisson rectangular model by constraining the first and last interval of a precipitation event to contain precipitation and (b) continuous sigmoid functions of the multiplicative weights to consider the scale-dependency in the disaggregation of precipitation events of different durations.

The constrained cascade model was evaluated in its ability to disaggregate observed precipitation events in comparison to existing MRC models. For that, we used a 20-year record of hourly precipitation at six stations across Germany. The constrained cascade model showed a pronounced better agreement with the observed data in terms of both the temporal pattern of the precipitation time series (e.g. the dry and wet spell durations and autocorrelations) and event characteristics (e.g. intra-event intermittency and intensity fluctuation within events). The constrained cascade model also slightly outperformed the other MRC models with respect to the intensityfrequency relationship.

To assess the performance of the coupled Poisson rectangular pulse and constrained cascade model, precipitation events were stochastically generated by the Poisson rectangular pulse model and then disaggregated by the 
constrained cascade model. We found that the coupled model performs satisfactorily in terms of the temporal pattern of the precipitation time series, event characteristics and the intensity-frequency relationship.

Keywords: rainfall generator, disaggregation, precipitation event, autocorrelation, within-event variability, intra-event intermittency

\section{Introduction}

2 Precipitation is highly variable at different temporal scales, e.g. annual, 3 seasonal, and also within storms (Berndtsson and Niemczynowicz, 1988; Em4 manuel et al., 2012; Samuel and Sivapalan, 2008) with different statistic prop5 erties at each scale (Molini et al., 2010). Generally, precipitation time series 6 can be described as sequences of precipitation events, characterized by their 7 duration and intensities, which are separated by dry periods of varying du8 rations (Bonta and Rao, 1988). Within-storm variability manifests itself by 9 intensity fluctuations as well as intra-event intermittency (precipitation-free phases within events).

Precipitation event characteristics and within-storm precipitation variability are of high importance for fast hydrological processes such as interception, stemflow, surface runoff, preferential flow, erosion, and solute dissipation from surface soils (e.g. Dunkerley, 2014, 2012; Van Stan et al., 2016; McGrath et al., 2008; Nel et al., 2016; Wiekenkamp et al., 2016; Hearman and Hinz, 2007). They are in turn also influencing flood generation in small catchments and in the urban context (Berne et al., 2004; Singh, 1997; 
Jothityangkoon and Sivapalan, 2001; Schilling, 1991) as well as water quality (Adyel et al., 2017; Borris et al., 2014; Weyhenmeyer et al., 2004). Furthermore, ecological processes are triggered by precipitation variability in short timescales (Huxman et al., 2004). The transformation between atmospheric input and hydrological and ecohydrological response is strongly non-linear whereby single extreme events may be of higher importance than gradual changes over a long time (Parmesan et al., 2000).

The influence of sub-daily rainfall on hydrological and ecohydrological processes can be investigated in Monte Carlo simulations in which multiple realisations or long time series of sub-daily precipitation are used as inputs to process-based models (e.g. Ding et al., 2016; McGrath et al., 2010, 2008) - Multiple realisations of precipitation time series are required to assess the role of multi-scale rainfall variability on the exceedance probability of hydrological threshold processes such as preferential flow and surface runoff (e.g. Struthers et al., 2007; Mandapaka et al., 2009). The results of these Monte Carlo simulations can furthermore be integrated in probabilistic frameworks for decision-making purposes (e.g. Hipsey et al., 2003). To obtain multiple realisations or long time series of sub-daily precipitation, stochastic modelling approaches have been widely employed to disaggregate observed precipitation time series to higher temporal resolution (e.g. Olsson, 1998) or to generate high temporal resolution time series directly (e.g. Haberlandt et al., 2008) . Among other approaches (e.g. Koutsoyiannis et al., 2003; Kossieris et al., 2016; Lombardo et al., 2017; Gyasi-Agyei, 2011), multiplica- 
tive microcanonical random cascade (MRC) models have been developed and applied to disaggregate observed precipitation from defined coarser to higher temporal resolution (e.g. monthly to daily, daily to hourly and sub-hourly) by several authors (e.g. Licznar et al., 2011a; Thober et al., 2014; Förster et al., 2016; Müller and Haberlandt, 2015). Stochastic precipitation models need to preserve the statistical properties of precipitation consistently across timescales (Lombardo et al., 2012; Paschalis et al., 2014). Therefore, it is necessary to take into account the temporal scaling behaviour of precipitation which can be described using multifractal concepts (e.g. Schertzer and Lovejoy, 1987; Veneziano and Langousis, 2010). The scaling behaviour itself varies in space and time (e.g. Molnar and Burlando, 2008; Langousis and Veneziano, 2007). The description of temporal scaling furthermore depends on whether continuous time series or intrastorm data are used (Veneziano and Lepore, 2012). For reviews on this topic the reader is referred to Veneziano et al. (2006) and Schertzer and Lovejoy (2011).

As the scaling behaviour of precipitation varies between temporal scales, consistency across timescales is aspired by coupling stochastic models for coarser timescales with those for finer timescales (e.g. Koutsoyiannis, 2001; Fatichi et al., 2011; Paschalis et al., 2014; Kossieris et al., 2016).

The temporal resolution of precipitation time series required depends on the process of interest. Urban hydrology, in particular overland flow typically requires time steps of less than 6 minutes (Berne et al., 2004). Hourly resolution may be sufficient for modelling flood events at the catchment scale 
(Ding et al., 2016). In fact, Sikorska and Seibert (2018) investigated the adequate temporal resolution of rainfall for discharge modeling and showed that hourly precipitation resolution may be used for catchment areas as small as $16 \mathrm{~km}^{2}$. To be applied in ecohydrological applications, precipitation models especially need to preserve statistical precipitation properties relevant for hydrological and landsurface processes. Due to the non-linearity in the rainfall-runoff transformation, the intensity-frequency relationship of precipitation is of general importance for hydrological, ecological, and landsurface processes (e.g. Kusumastuti et al., 2007; Fiener et al., 2013; Knapp et al., 2002). The temporal pattern of precipitation time series plays a major role for many hydrological and biogeochemical processes, e.g. the dry spell duration influences nutrient accumulation and exports (Adyel et al., 2017). The temporal structure quantified by the autocorrelation in precipitation time series is relevant for wet and dry cycles. Intra-event intermittency is relevant for landsurface processes (Dunkerley, 2015; Von Ruette et al., 2014). Intensity fluctuations within events influence the partitioning between infiltration and surface runoff (Dunkerley, 2012) whereby higher intensities at a later time in the event result in a higher peak discharge (Dolšak et al., 2016).

As pointed out by Dunkerley (2008), the conservation of event characteristics is crucial for an adequate simulation of various (eco-)hydrological processes. One option towards a better representation of these characteristics is to obtain sub-daily precipitation time series from generated events rather than from generated daily values. This can be realised by generating 
alternating sequences of dry periods and precipitation events by the Poisson rectangular pulse models (e.g. Rodriguez-Iturbe et al., 1987; Bonta and Rao, 1988; Bonta, 2004) and disaggregating these events to higher temporal resolution by MRC models (e.g. Menabde and Sivapalan, 2000). Additionally it is necessary to overcome the tendency of MRC models to underestimate the temporal autocorrelation for small lag times reported by various studies (e.g. Paschalis et al., 2014; Müller, 2016; Pui et al., 2012).

However, coupling Poisson rectangular pulse models and MRC models is not straightforward as the temporal structures between these models are inconsistent. Firstly, MRC models which are developed to downscale from a fixed coarser to fine temporal resolution (e.g. daily to hourly) would not conserve the precipitation events generated by the Poisson model but tend to underestimate the event durations. Furthermore, the timescale-dependent probabilities of the multiplicative weights used in the MRC model can be parameterised by aggregation for multiples of the observed time step only. Menabde and Sivapalan (2000) approached these issues by applying a modified MRC model, which does not allow for precipitation-free phases within events, and thus conserves event durations at the cost of not capturing intraevent intermittency.

We present a new coupling approach of the Poisson rectangular pulse model and the MRC model for the stochastic generation of precipitation events and disaggregation to continuous equidistant high-frequency precipitation time series. In this approach, the MRC model is conditioned in such a 
way that the first and the last interval of each precipitation event are forced to contain precipitation. This model, henceforth referred to as constrained cascade model, allows to both conserve event durations and consider intraevent intermittency. Furthermore, the time-scale dependent probabilities of the multiplicative weights for $1 / 0,0 / 1$ or $\mathrm{x} /(1-\mathrm{x})$-splitting are described by sigmoid functions to obtain values for time steps other than multiples of the time step of the observed data. A comparison between different cascade approaches to disaggregate observed precipitation events is presented at the example of six precipitation stations across Germany. Finally, the general performance of the coupled Poisson and cascade model is evaluated with respect to the intensity-frequency relationship, the temporal pattern of the entire time series, and event characteristics.

\section{Methods}

\subsection{Poisson rectangular pulse model}

\subsubsection{Model description}

The concept of the Poisson rectangular pulse model is based on the assumption that alternating sequences of precipitation events and interstorm periods can be described by a Poisson process, i.e. interstorm period durations between independent precipitation events are assumed to be exponentially distributed whereas precipitation events are considered to be of zero duration (Bonta and Rao, 1988). In reality, precipitation events have a finite duration longer than zero. Therefore, Restrepo-Posada and Ea- 
gleson (1982) proposed to separate precipitation records into statisticallyindependent events based on a threshold for the minimum duration of precipitationfree phases between two events. This threshold is called minimum dry period duration, $d_{d, m i n}$, (Bonta, 2004), critical duration (Bonta and Rao, 1988), or minimum inter-event time (Medina-Cobo et al., 2016). Based on the minimum dry period duration, continuous precipitation time series can be discretized into sequences of statistically-independent precipitation events and alternating dry periods. This allows determining event durations $d_{e}$, mean event intensities $i_{e}$, and dry period durations $d_{d}$. The Poisson rectangular pulse model generates dry period durations from exponential distributions which are shifted by the minimum dry period duration. Event durations are generated from exponential distributions. To consider the negative correlation between event durations and mean event intensities, Robinson and Sivapalan (1997) developed an approach whereby storm duration classes are derived from the observed event durations and gamma distributions are fitted to the mean event intensities of the respective storm duration class.

\subsubsection{Model parameterisation}

To parameterise the Poisson rectangular pulse model, we firstly determined the minimum dry period duration $d_{d, \min }$ from precipitation records using the approach described by Restrepo-Posada and Eagleson (1982). At first, the frequencies of the lengths of consecutive dry phases in the continuous time series have been recorded in a histogram, whereby the bin width of 
the histogram corresponds to the temporal resolution of the input data. If the coefficient of variation of the lengths of consecutive dry phases contained in the histogram is higher than one (i.e. the coefficient of variation of an exponential distribution), the smallest bin of the histogram is being omitted. This procedure is repeated subsequently until the coefficient of variation is smaller than one so that according to Restrepo-Posada and Eagleson (1982) a Poisson process can be assumed. We then discretized the observed time series into events and recorded the dry period durations $d_{d}$ between the events, the event durations $d_{e}$, and the mean event intensities $i_{e}$. We fitted shifted exponential distributions for the dry period durations, exponential distributions for the event durations, and gamma distributions of the mean intensities for four event duration classes. The model parameters were not specified for individual seasons as they did not exhibit pronounced seasonality for the stations selected.

\subsection{Constrained microcanonical multiplicative cascade model to disaggregate} events

\subsubsection{Model description}

To disaggregate the precipitation events generated by the Poisson model into continuous precipitation time series of high temporal resolution, we developed a modified MRC model with a branching number of two based on the MRC model by Olsson (1998). In the first level of disaggregation, the total event volume is apportioned to the first and the second halves (boxes) of the 
event duration. Each of these boxes is then furthermore branched into two parts. Branching with no precipitation in the first box and all precipitation being apportioned to the second box is called 0/1-splitting, branching with all precipitation being apportioned to the first box is called 1/0-splitting and branching with a fraction of the precipitation apportioned to the first box and the remainder to the second box is referred to as $\mathrm{x} /(1-\mathrm{x})$-splitting. Branching is realised through randomly assigned multiplicative weights $W_{1}$ and $W_{2}$ with timescale-dependent probabilities $\mathrm{P}(0 / 1), \mathrm{P}(1 / 0)$ and $\mathrm{P}(\mathrm{x} /(1-\mathrm{x})$.

$$
W_{1}, W_{2}= \begin{cases}0 \text { and } 1 & \text { with probability } \mathrm{P}(0 / 1) \\ 1 \text { and } 0 & \text { with probability } \mathrm{P}(1 / 0) \\ x \text { and }(1-x) & \text { with probability } P(x /(1-x)) ; 0<x<1 .\end{cases}
$$

To conserve event durations we modified the cascade model by Olsson (1998) so that the branching of the box at the beginning of the event is constrained to $1 / 0$-splitting or $\mathrm{x} /(1-\mathrm{x})$-splitting, whereas the branching of the box at the end of the event is constrained to $0 / 1$-splitting or $\mathrm{x} /(1-\mathrm{x})$ splitting. Position classes (starting, enclosed, ending and isolated box) as well as volume classes (below / above mean precipitation of the respective position class) are taken into account similarly to the approach by Olsson (1998). Following the approach by Menabde and Sivapalan (2000), we applied breakdown coefficients to consider the timescale-dependence on the multiplicative weights in case of $\mathrm{x} /(1-\mathrm{x})$-splitting. The probability density 
functions of the breakdown coefficients were approximated by symmetrical beta distributions for each level of aggregation. The temporal scaling of the parameter $a$ of these beta distributions is implemented by

$$
a(t)=a_{0} \times t^{-H}
$$

Whereby $a(t)$ is the timescale-dependent parameter of the beta distribution and $a_{0}$ and $H$ are constants estimated from the data. The timescaledependent probabilities of the multiplicative weights for $0 / 1,1 / 0$, and $\mathrm{x} /(1-\mathrm{x})$ splitting are estimated by successive aggregation of the observed precipitation data for discrete temporal resolutions (input resolution times two to the power of number of aggregations). The Poisson model results in highly variable event durations which mostly do not correspond to the temporal resolutions for which the cascade model is parameterised through aggregation. Therefore, to obtain parameters for the disaggregation of the events generated by the Poisson model, continuous functions of the probabilities of the multiplicative weights are required. These functions need to maintain $P(0 / 1)+P(1 / 0)+P(x /(1-x))=1$ for all timescales, i.e. also timescales smaller and coarser than the input resolution times two to the power of the highest number of aggregations used in the parameterisation. Thus, they need to have asymptotes for both $t \rightarrow 0$ and $t \rightarrow \infty$. Thus, we calculated the timescale-dependent probabilities of the multiplicative weights $P(t)$ by 
sigmoid functions of the form

$$
P(t)=P_{\infty}+\frac{P_{0}-P_{\infty}}{\left[1+(s \times t)^{n}\right]^{1-\frac{1}{n}}} .
$$

With $P_{0}$ and $P_{\infty}$ as the probabilities of the multiplicative weights for $\mathrm{t} \rightarrow$ 0 and $\mathrm{t} \rightarrow \infty$, and $s$ and $n$ as shape parameters of the sigmoid function. Using the MRC model for the disaggregation of events of different duration will result in very different final time steps. However, equidistant time steps are required for comparisons with observed data. Therefore, the disaggregation is performed until the temporal resolution of the cascade is higher than the specified output resolution. Thereafter, the time step is harmonized by merging the time series to the specified output resolution assuming a uniform transformation. The amount of precipitation of the first time step at the coarser resolution is determined as the sum of the volume of the first time step at higher resolution plus the proportion of the volume of the second time step at higher resolution for the fraction of time which the second time step at higher resolution intersects the first time step at coarser resolution and so on.

\subsubsection{Model parameterisation}

The MRC models was parameterised by successively aggregating the observed precipitation time series to coarser temporal resolutions; five levels of aggregation were used (resulting in the coarsest time step of 32 hours). The model parameters are not specified for individual seasons as they did not ex- 
hibit pronounced seasonality for the stations selected, which has been shown in cascade model applications for Germany and also Brazil, Great Britain and Sweden (e.g. Müller, 2016; Güntner et al., 2001; Olsson, 1998).

\subsection{Comparison with other cascade models for disaggregating events}

To evaluate the constrained cascade model regarding its performance of disaggregating precipitation events, we compared it to the cascade models developed by Olsson (1998), henceforth referred to as C1, and by Menabde and Sivapalan (2000), henceforth C2. The principle of these cascade models is illustrated in Fig. 1 at the example of a precipitation event of $16 \mathrm{~h}$ duration and $42 \mathrm{~mm}$ depth (mean event intensity $=2.625 \mathrm{~mm} / \mathrm{h}$ ). Designed for disaggregating daily precipitation, the cascade by Olsson (1998) (C1) allows for $1 / 0,0 / 1$ and $\mathrm{x} /(1-\mathrm{x})$ splitting in every box. The cascade model by Menabde and Sivapalan (2000) (C2), designed for disaggregating precipitation events, conserves event durations by applying $\mathrm{x} /(1-\mathrm{x})$ splitting exclusively. The constrained cascade model (C3) conserves event durations and also allows for dry intervals within precipitation events. The model comparison is conducted based on observed precipitation events, which have been determined from the observed precipitation time series based on the on the minimum dry period duration $d_{d, \min }$ as estimated for the respective station. We then disaggregated these events using the three cascade models. 

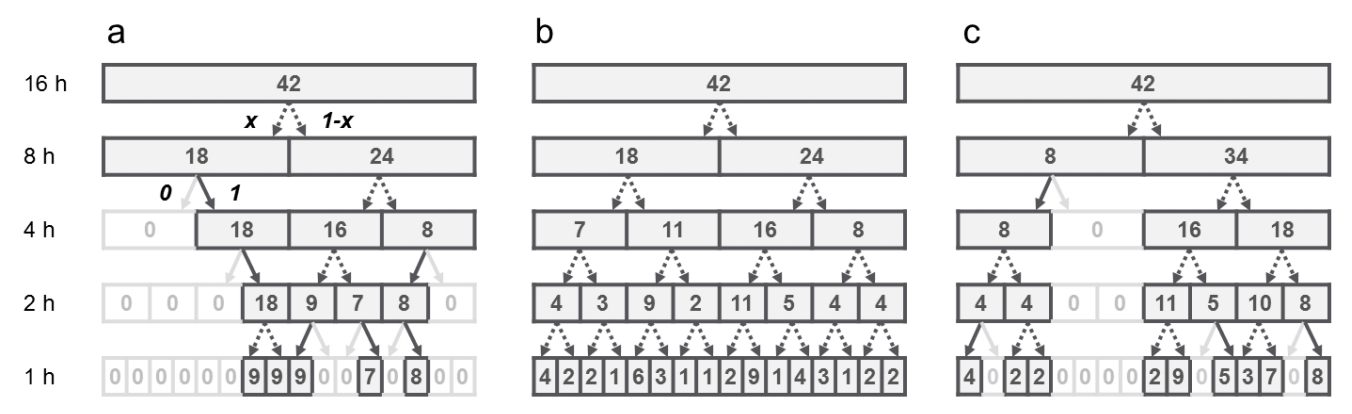

Figure 1: Disaggregation of a $16 \mathrm{~h}$ precipitation event of $42 \mathrm{~mm}$ depth using different cascade approaches (simplified schematics, adapted from Olsson (1998) and Müller and Haberlandt (2018)). a) Cascade model by Olsson (1998) (C1), b) Cascade model by Menabde and Sivapalan (2000) (C2), c) Constrained cascade developed in this study (C3).

\subsection{Evaluation strategy}

The coupled Poisson and cascade model is evaluated regarding its ability to generate high-frequency precipitation time series with similar statistical characteristics as the observed data. As the coupled model is developed to generate precipitation time series as input for hydrological models, we chose evaluation criteria which are relevant for hydrological processes. As pointed out by Stedinger and Taylor (1982) the credibility of a stochastic model is enhanced if it reproduces statistics that are not used in the model parameterisation. Thus, the evaluation of the coupled Poisson and MRC model requires criteria which can be determined from both observed and generated data and which are independent from assumptions of the models. To that end, we computed criteria which describe the intensity-frequency relationship and the temporal pattern of the entire time series. The intensity-frequency relationship was evaluated in terms of fractions of intervals within certain in- 
tensity ranges and statistical characteristics of the intensities of wet intervals (mean value, median, standard deviation and skewness). To compare temporal patterns of the entire time series, we assessed the dry spell duration, wet spell duration and autocorrelation. The autocorrelation, which describes the temporal structure of the data, was evaluated by Spearman's rank autocorrelation as precipitation intensities are not normally distributed. For comparability with the literature, we also computed Pearson's autocorrelation. Both have been computed using the acf function implemented in $\mathrm{R}(\mathrm{R}$ Core Team, 2016) applied to the ranks of the data and the data, respectively. Furthermore, we compared event characteristics, namely the intra-event intermittency and the intensity fluctuation within events, which depend on the Poisson model's assumptions on independent precipitation events. The intra-event intermittency was computed as the dry ratio within precipitation events similar to the definition by Molini et al. (2001). The intensity fluctuation within events was described in terms of event profiles as suggested by Acreman (1990). For a standardized comparison of events of variable duration, we computed the fraction of precipitation in quarters of the event duration for events with durations of multiples of four hours only.

The criteria against which the model is evaluated include standard statistics commonly used to assess the performance of stochastic precipitation models (e.g. mean intensity, standard deviation of the intensity and autocorrelation) (e.g. Pui et al., 2012; Onof and Wheater, 1993).

The criteria used for model evaluation are described in Tab. 1. All criteria 
have been calculated at hourly time step which is the highest resolution of the observed data.

The general performance of the coupled model was furthermore evaluated with respect to return periods of hourly and daily precipitation intensities. Similar to the method described in Müller and Haberlandt (2018) we chose the highest 40 values of each observed time series and each realisation, respectively, and determined the return periods $\mathrm{T}$ of these values according to the plotting positions using equation 3 as documented in DWA-A 531 (2012):

$$
T=\frac{L+0.2}{k-0.4} \times \frac{M}{L}
$$

with $\mathrm{T}$ as the return period, $\mathrm{L}$ as the sample size (in our case: 40), $\mathrm{M}$ as the number of years of the observed record (in our case: 20), and $\mathrm{k}$ as the running index of the sample values from highest to lowest. We compared precipitation intensities for return periods of $0.5,1,2,5.6$ and 12.6 years for both hourly and daily extreme precipitation values.

\section{Data}

We used a twenty-year record (1996-2015) of hourly precipitation data at six stations across Germany: Cottbus, Köln-Bonn, Lindenberg, Meiningen, München-Flughafen and Rostock-Warnemünde (Tab. 2). Cottbus, Lindenberg, Meiningen and München-Flughafen are characterised by humid continental climate (more precisely Köppen-Geiger classification Dfb) according 
to Peel et al. (2007). Rostock-Warnemünde lies at the transition between oceanic climate and humid continental climate (Köppen-Geiger classification $\mathrm{Cfb}$ - Dfb) and Köln is characterised by oceanic climate (Köppen-Geiger classification $\mathrm{Cfb})$. All collecting funnels have a surface area of $200 \mathrm{~cm}^{2}$. The data have been collated by the German Weather Service (Deutscher Wetterdienst, DWD) and have been available to the authors with a resolution of $0.1 \mathrm{~mm}$ and a temporal resolution of one hour.

\section{Results}

\subsection{Model parameterisation}

\subsubsection{Poisson rectangular pulse model}

The minimum dry period duration $d_{d, \text { min }}$ which is a prerequisite to parameterise the Poisson model ranges between $14 \mathrm{~h}$ (München-Flughafen) and $22 \mathrm{~h}$ (Rostock-Warnemünde) as shown in Tab. 3. The mean dry period duration $d_{d, m e a n}$ varies between $63 \mathrm{~h}$ (Köln-Bonn) and 75 h (Rostock-Warnemünde), the mean event duration $d_{e, \text { mean }}$ varies between $17 \mathrm{~h}$ (München-Flughafen) and $24 \mathrm{~h}$ (Rostock-Warnemünde). The mean event intensities $i_{e, m e a n}$ amount to approximately $0.50 \mathrm{~mm} / \mathrm{h}$ with highest values for München-Flughafen $(0.55 \mathrm{~mm} / \mathrm{h})$ and lowest values for Meiningen and Rostock-Warnemünde $(0.44 \mathrm{~mm} / \mathrm{h})$.

\subsubsection{Constrained cascade model} The timescale-dependent probabilities of the multiplicative weights $P(t)$ are shown in Fig. 2 for the position and volume class enclosed below of the 
station Lindenberg. The sigmoid functions fitted through those points, which are necessary for disaggregating events of different durations, are shown as lines. Figure A.1 illustrates these sigmoid functions for all stations for the enclosed position class. The probabilities of the multiplicative weights of $\mathrm{x} /(1-\mathrm{x})$-splitting are generally highest and decrease with timescale. They are higher in case of the volume class above than in the volume class below. The probabilities of the multiplicative weights of $0 / 1$ and $1 / 0$-splitting are more or less similar. These relationships also depend on the respective volume and position classes as summarized in Tab. 4. All stations show small differences between the respective $P_{\infty}$ values and similar patterns in their temporal scaling.

The parameter $a$ of the symmetrical beta distribution in case of the $\mathrm{x} /(1-$ $\mathrm{x}$ )-splitting generally decreases with coarser timescale. In case of the enclosed position class, the parameter $a$ is higher than 1 for temporal resolutions of less than 8 hours (3 aggregations of hourly data), i.e. the multiplicative weights can be described by a unimodal beta distribution. For coarser temporal resolutions the parameter $a$ is smaller than 1 , so that the beta distribution is "U-shaped" bimodal. The scale-dependence of $a$ is significant in case of the starting below, enclosed above, enclosed below, ending above, ending below and isolated below position and volume class (Tab. 5). All stations show relatively similar patterns with highest values for $a$ for the class isolated below and low values for $a$ for isolated above, starting above and ending above. The values of the parameter $H$ describing the scale-dependence of the 


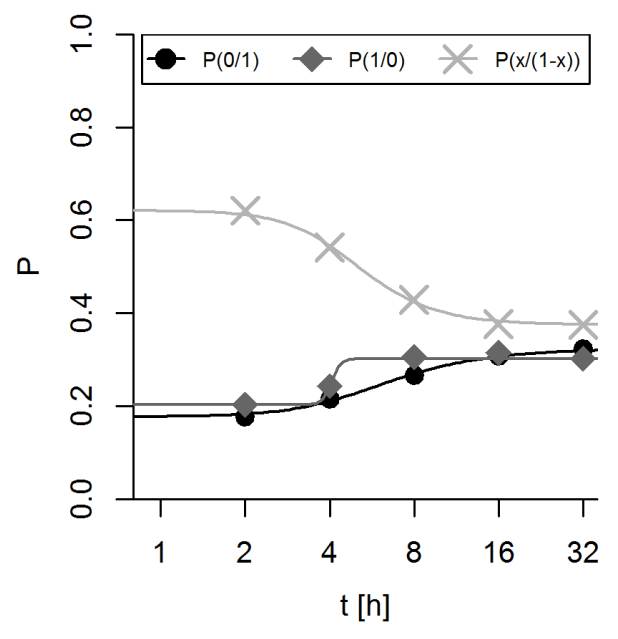

Figure 2: Timescale dependent probabilities of the multiplicative weights $P(t)$ (position and volume class enclosed below of the station Lindenberg). Points show the probabilities of the multiplicative weights determined by aggregating the data, lines show the fitted sigmoid functions.

parameter $a$ are very similar between the different stations of the respective position and volume class when significant relationships exist.

\subsection{Evaluation of disaggregation approaches}

To compare the different disaggregation approaches, the precipitation time series at the respective stations have been divided into events using the minimum dry period duration $d_{d, \min }$ estimated for each station. Based on these discretized observed events 60 realisations each of hourly time series have been generated using the cascade models developed by Olsson (1998) (C1), by Menabde and Sivapalan (2000) (C2), and by the constrained cascade presented in this paper (C3). The evaluation criteria are shown in Tab. 6 for the Lindenberg weather station and furthermore tabulated for all stations in 
the appendix (Tab. A.1 - A.5).

\subsubsection{Intensity-frequency relationships (entire time series)}

The observed precipitation data are characterised by a dry ratio of about $90 \%$, a fraction of intervals $>0 \mathrm{~mm} / \mathrm{h}$ and $\leq 0.1 \mathrm{~mm} / \mathrm{h}$ between $2.5 \%$ (Lindenberg, Rostock-Warnemünde) and $3.2 \%$ (Meiningen), and a fraction of intervals $>0.1 \mathrm{~mm} / \mathrm{h}$ and $\leq 10 \mathrm{~mm} / \mathrm{h}$ between $6.5 \%$ (Lindenberg) and 8.6 \% (Köln-Bonn) Tab. 6,Tab. A.1). Intensities higher than $10 \mathrm{~mm} / \mathrm{h}$ occur in $0.02 \%$ (Lindenberg, Meiningen) to $0.04 \%$ (Köln-Bonn, München) of the intervals. The mean intensity of wet intervals ranges from $0.66 \mathrm{~mm} / \mathrm{h}$ (Meiningen) to $0.80 \mathrm{~mm} / \mathrm{h}$ (München-Flughafen) with standard deviations of about $1.3 \mathrm{~mm} / \mathrm{h}$, skewness between 6 and 10 and median of $0.3 \mathrm{~mm} / \mathrm{h}($ Cottbus, Lindenberg, Meiningen) or 0.4 mm/h (Köln-Bonn, München-Flughafen, Rostock-Warnemünde) (all stations in Tab. A.2).

Cascade model $\mathrm{C} 1$ results in an about $5 \%$ higher dry ratio and $50 \%$ less intervals in the range between $>0 \mathrm{~mm} / \mathrm{h}$ and $\leq 0.1 \mathrm{~mm} / \mathrm{h}$ than the observed data for all stations, overall the relative error for the fraction of intervals $\leq 0.1$ $\mathrm{mm} / \mathrm{h}$ amounts to approximately $3 \%$. The fraction of intervals $>0.1 \mathrm{~mm} / \mathrm{h}$ and $\leq 10 \mathrm{~mm} / \mathrm{h}$ is underestimated by about $30 \%$, whereas the fraction of intervals $>10 \mathrm{~mm} / \mathrm{h}$ is overestimated by about $150 \%$. The intensities of wet intervals generated by cascade model $\mathrm{C} 1$ are on average $60 \%$ higher than those of the observations, their standard deviation shows a relative error of $70 \%$, their skewness shows a relative error of $-15 \%$ and their median is 
approximately $40 \%$ higher than that of the observed data.

Cascade model $\mathrm{C} 2$ generates dry ratios which are approximately $15 \%$ too low for all stations, whereas the fraction of intervals $>0 \mathrm{~mm} / \mathrm{h}$ and $\leq 0.1$ $\mathrm{mm} / \mathrm{h}$ is $350 \%$ too high compared with the observed data, yet the total fraction of intervals $\leq 0.1 \mathrm{~mm} / \mathrm{h}$ is in good agreement with the observation (relative error of $-3 \%$ ). The fraction of intervals $>0.1 \mathrm{~mm} / \mathrm{h}$ and $\leq 10 \mathrm{~mm} / \mathrm{h}$ is overestimated by about $40 \%$, whereas the fraction of intervals $>10 \mathrm{~mm} / \mathrm{h}$ is underestimated by about $50 \%$. The intensities of wet intervals generated by cascade model $\mathrm{C} 2$ are on average $50 \%$ too low and show a $40 \%$ too low standard deviation, an $8 \%$ too high skewness and an $80 \%$ too low median compared with the observations.

Cascade model C3 preserves the dry ratio well (relative error of less than $1 \%$ for all stations), but overestimates the fraction of intervals between $>0$ $\mathrm{mm} / \mathrm{h}$ and $\leq 0.1 \mathrm{~mm} / \mathrm{h}$ by about $20 \%$, all in all the fraction of intervals $\leq 0.1 \mathrm{~mm} / \mathrm{h}$ is in good agreement with the observations (relative error of less than $1 \%$ ). The fraction of intervals $>0.1 \mathrm{~mm} / \mathrm{h}$ and $\leq 10 \mathrm{~mm} / \mathrm{h}$ is on average underestimated by $2 \%$, whereas the fraction of intervals $>10 \mathrm{~mm} / \mathrm{h}$ is overestimated by about $20 \%$. The intensities of wet intervals generated by cascade model C3 is on average 5\% too low, and show an approximately $10 \%$ too high standard deviation, except for the station Rostock-Warnemünde a too low skewness and $20 \%$ too low median in comparison to the observed data. 


\subsubsection{Temporal pattern (entire time series)}

The observed time series are characterised by mean dry spell durations of $21.3 \mathrm{~h}$ (Köln-Bonn) to $27.6 \mathrm{~h}$ (Lindenberg), the dry spell durations exhibit a standard deviation of approximately $50 \mathrm{~h}$ and a skewness between $4.3 \mathrm{~h}$ and $4.9 \mathrm{~h}$ (all stations in the appendix Tab. A.3). The mean wet spell durations range from $2.6 \mathrm{~h}$ (Rostock-Warnemünde) to $3.0 \mathrm{~h}$ (München-Flughafen), their standard deviations is between $2.6 \mathrm{~h}$ and $3.5 \mathrm{~h}$ and their skewness between 3.1 and 3.9.

Cascade model $\mathrm{C} 1$ results in twice as long mean dry spell durations than the observations, its standard deviation is overestimated by approximately $40 \%$ and its skewness is underestimated by $40 \%$ (averages for all stations). The model generates approximately $1 \mathrm{~h}$ or $30 \%$ longer mean wet spell durations, the standard deviation of the wet spell duration is well preserved with a relative error ranging between $-9 \%$ and $15 \%$ and the skewness is underestimated by about $30 \%$.

Cascade model $\mathrm{C} 2$ generates mean dry spell durations which are almost three times as long as the observations on average for all stations, both their standard deviation and skewness are overestimated by approximately $40 \%$. The wet spell durations generated by $\mathrm{C} 2$ are between 5 and 9 times longer than the observed wet spell durations and show a standard deviation which is $700 \%$ higher and a skewness which is $30 \%$ lower compared to the observed wet spell durations.

Cascade model C3 overestimates the mean dry spell durations by about 
$20 \%$ and their standard deviation by $10 \%$, the skewness is underestimated by $10 \%$ for all stations. The mean wet spell durations generated by this model are about $1 \mathrm{~h}$ or $30 \%$ longer than those of the observed data, their standard deviation is well represented with a relative error of less than between $-5 \%$ and $10 \%$ and similar to the other cascade models the skewness is underestimated by $30 \%$.

Spearman's autocorrelation of the observed hourly precipitation time series is 0.60 to 0.65 for a lag time of $1 \mathrm{~h}, 0.34$ to 0.42 for a lag time of 3 h, 0.19 to 0.28 for a lag time of $6 \mathrm{~h}$ and 0.12 to 0.20 for a lag time of $9 \mathrm{~h}$ (Tab. A.4). The lowest values occur at Rostock-Warnemünde and the highest at München-Flughafen. They strictly decline in relation to these lag times (Fig. 3). Pearson's autocorrelation of the observed hourly precipitation time series is 0.35 to 0.41 for a lag time of $1 \mathrm{~h}, 0.12$ to 0.15 for a lag time of $3 \mathrm{~h}$, 0.06 to 0.09 for a lag time of $6 \mathrm{~h}$ and 0.04 to 0.06 for a lag time of $9 \mathrm{~h}$ with less consistencies between the stations than for Spearman's autocorrelation.

Cascade model C1 shows a slight overestimation of the Spearman's rank autocorrelation for lag $1 \mathrm{~h}$ by about $15 \%$ and an underestimation for lag $6 \mathrm{~h}$ and beyond (e.g. relative error for lag $6 \mathrm{~h}$ on average $-5 \%$ and relative error for lag $9 \mathrm{~h}-20 \%$, for all stations see the appendix A.4). Pearson's autocorrelation is preserved well for a lag time of $1 \mathrm{~h}$ (deviation between data and cascade model $\mathrm{C} 1$ results of less than $5 \%$ ), but underestimated for longer lag times (relative errors of around $-20 \%$ for a lag time of $3 \mathrm{~h}$ and $-50 \%$ for a lag time of $6 \mathrm{~h}$ and $9 \mathrm{~h}$ ). 
Cascade model $\mathrm{C} 2$ generally results in higher autocorrelations than the data (overestimation of Spearman's rank autocorrelation by about $50 \%$ for a lag time of one hour, $120 \%$ for a lag time of 3 h, $190 \%$ for a lag time of $6 \mathrm{~h}$ and $240 \%$ for a lag time of 9 h, overestimation of Pearson's autocorrelation by approximately $50 \%$ for a lag time of one hour, $80 \%$ for a lag time of $3 \mathrm{~h}$, $90 \%$ for a lag time of $6 \mathrm{~h}$ and about $100 \%$ for a lag time of $9 \mathrm{~h}$ ).

Cascade model C3 preserves the autocorrelation in the data well with a slight overestimation of both Spearman's rank autocorrelation and Pearson's autocorrelation for a lag time of $1 \mathrm{~h}$ by about $10 \%$ and smaller relative errors for lag times up to $9 \mathrm{~h}$. For longer lag times the differences between individual realisations are pronounced and cascade model C3 underestimates the autocorrelations in the data.

The influence of the temporal sequence of dry and wet intervals on the autocorrelation function is shown by Spearman's rank autocorrelation and Pearson's autocorrelation for binarized time series (all values $>0 \mathrm{~mm}$ have been set to $1 \mathrm{~mm}$ ) in Fig 4 . It is evident that the autocorrelation of the binarised time series differs only slightly from the Spearman's rank autocorrelation for time series of continuous precipitation depth shown in Fig 3.

\subsubsection{Event characteristics}

The intra-event intermittency of the observed data can be described by a event dry ratio with a mean value between $29 \%$ (München-Flughafen) and $39 \%$ (Rostock-Warnemünde), a standard deviation of approximately 
$29.4 \%$, a skewness ranging from -0.1 (Meiningen, Rostock-Warnemünde) to 0.3 (München-Flughafen) and a median of approximately $36 \%$ (Tab. A.5). To visualise intensity fluctuation within events, the partitioning of the total precipitation depths to quarters of the event duration is displayed in Fig. 5 for Lindenberg and summarized in Tab. A.6 for all stations. As visible from the figure, the intensity fluctuations within events are very variable. On average, however, the partitioning to the respective quarters of the events is very similar for all stations, around $34 \%$ of the precipitation occurs within the first quarter of the event, $20 \%$ in the second quarter, $19 \%$ in the third quarter and $20 \%$ in the fourth quarter.

Cascade model $\mathrm{C} 1$ overestimates the mean dry ratio within events by about $50 \%$ and shows a $5 \%$ higher standard deviation of the dry ratio within events as well as a skewness around -0.5 for all stations. The median of the dry ratio within events is $60 \%$ higher than in the observed data. Cascade model $\mathrm{C} 1$ tends to distribute precipitation to the center of the event, so that the proportion of precipitation falling in the first and fourth quarter are underestimated by $30 \%$ and $20 \%$ respectively, whereas precipitation in the second and third quarter are overestimated by around $30 \%$ each.

Cascade model $\mathrm{C} 2$ results in an event dry ratio of less than $1 \%$, underestimates the standard deviation of the event dry ratio by $80 \%$, results in a skewness of 11 and a median event dry ratio of $0 \%$ for all stations. The model distributes the total event depth evenly to all the quarters within the event, so that the precipitation depth in the first and fourth quarter is $25 \%$ 
and $14 \%$ lower, respectively, whereas the precipitation depth in the second and third quarter is on average $25 \%$ and $29 \%$ higher, respectively, than in the observations.

Cascade model C3 shows an underestimation of dry intervals within events by around $15 \%$ on average and of their standard deviation by about $7 \%$ averaged over all stations. The model generates a skewness of the event dry ratio of around 0.3 . The median of the event dry ratio is underestimated by about $30 \%$. Cascade model C3 mimics the partitioning of the observed data with higher precipitation depth in the first and fourth quarter than in the second and third, however precipitation in the first quarter is underestimated by $10 \%$, whereas the relative errors for the other quarters are smaller than $\pm 5 \%$.

4.3. General performance of the coupled Poisson and constrained cascade model

The general model performance was evaluated by comparing statistics of observed precipitation time series with those of precipitation events generated by the Poisson rectangular pulse model and disaggregated by the constrained cascade model (C3). The results of the model evaluation are summarized in Tab. 7 at the example of the Lindenberg weather station and for all stations in the appendix in Tab. A.7 - Tab. A.14.

Additional to the criteria mentioned in Tab. 1 we compared the Poisson model parameters obtained from the observed data (Tab. 3) with those of the 

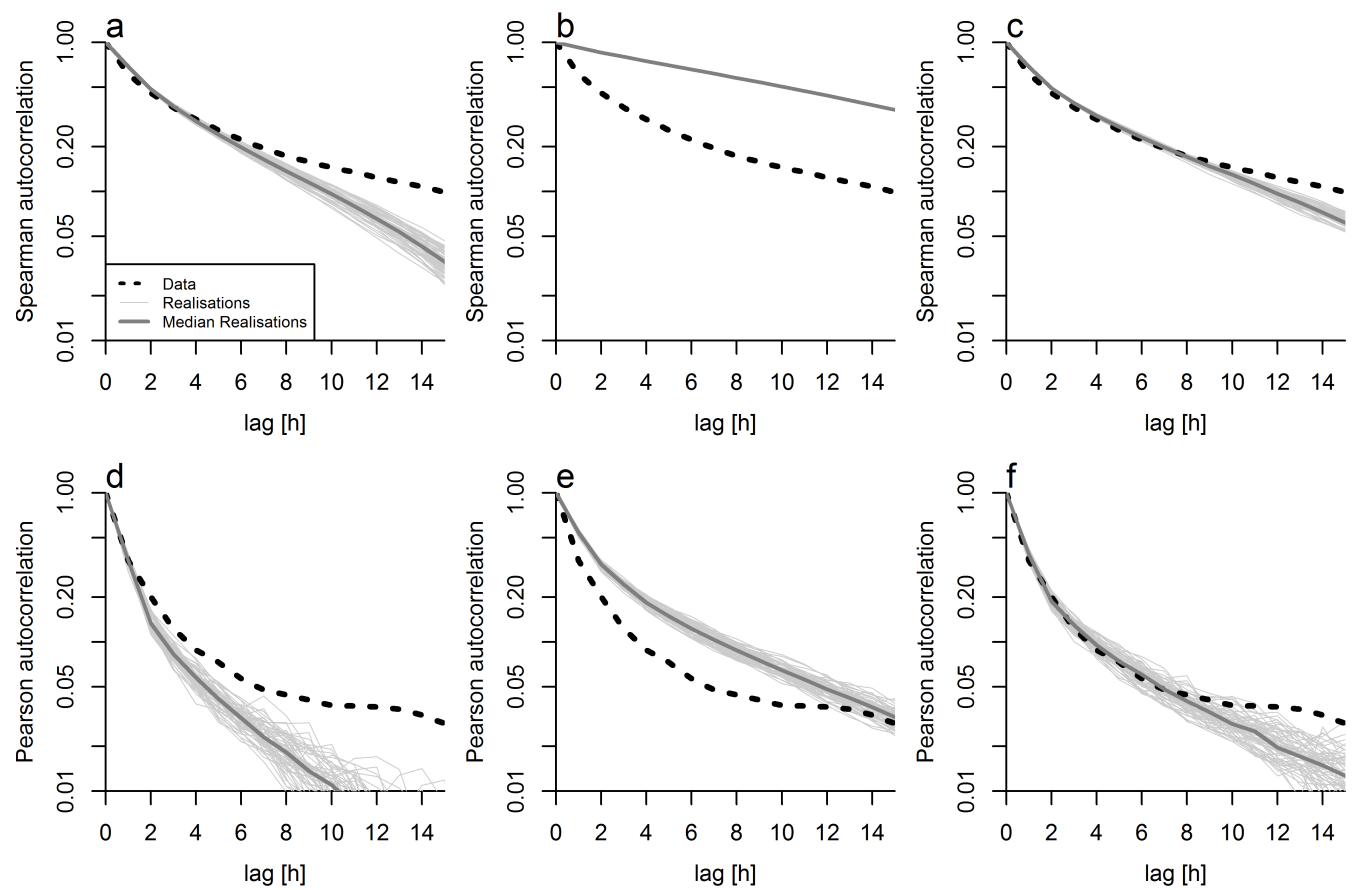

Figure 3: Autocorrelation of observed data and disaggregated events for the station Lindenberg. Upper row: Spearman's rank autocorrelation. a) Cascade Model C1, b) Cascade Model C2, c) Cascade Model C3. Lower row: Pearson's autocorrelation. d) Cascade Model C1, e) Cascade Model C2, f) Cascade Model C3
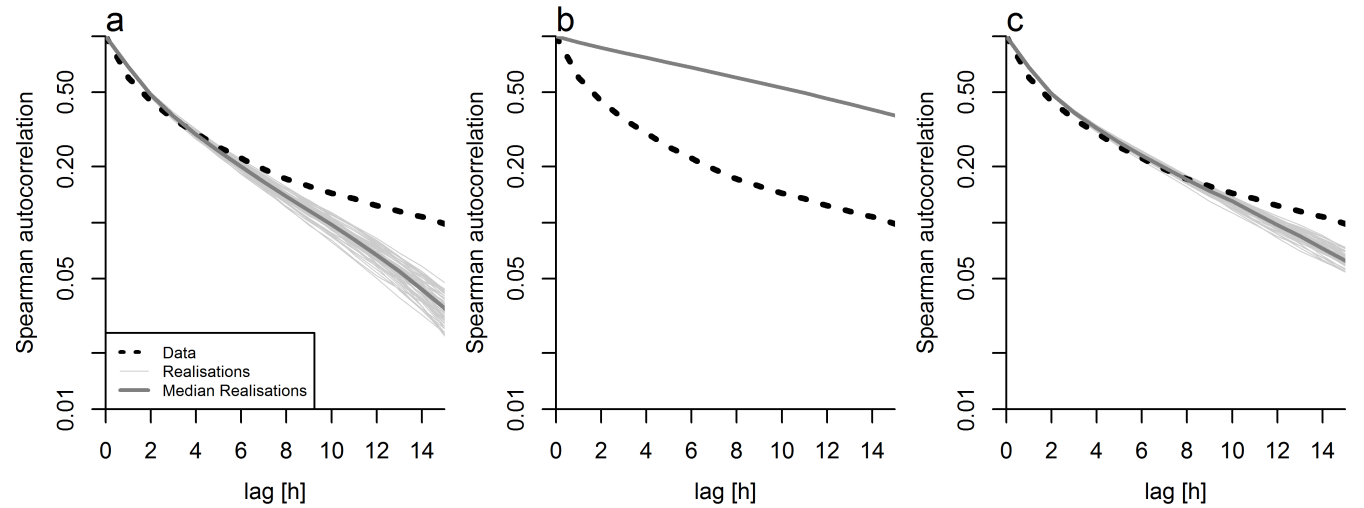

Figure 4: Autocorrelation of binarised observed data and disaggregated events for the station Lindenberg. a) Cascade Model C1, b) Cascade Model C2, c) Cascade Model C3 (Spearman's rank autocorrelation is equal to Pearson's autocorrelation for binarized values). 

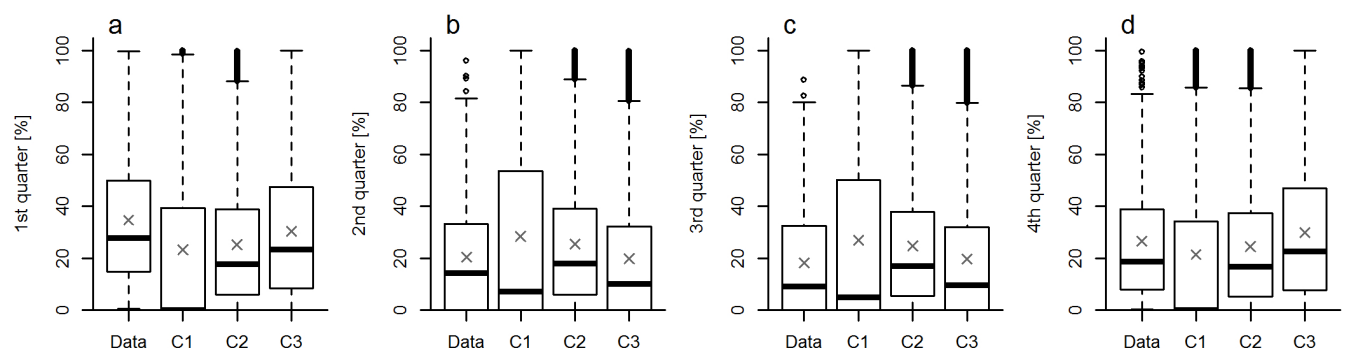

Figure 5: Partitioning of the total event depths to quarters of the event duration for the station Lindenberg: a) first quarter, b) second quarter, c) third quarter, d) fourth quarter for the Data, and the cascade models C1, C2 and C3. Boxplots include all events of all realisations, cross symbols represent mean values. To calculate this metric for precipitation events with durations of multiples of four, 396 out of the 1975 events in Lindenberg have been considered.

generated events (Tab. A.7). The mean dry period durations of the generated events correspond to those of the observations, the model shows a slight overestimation by about $1 \mathrm{~h}(1 \%)$. The simulated mean event durations are approximately $1 \mathrm{~h}$ longer than the observations for most stations which is roughly a difference of $6 \%$, in case of the station Lindenberg the mean event durations are underestimated by $2.6 \mathrm{~h}(15 \%)$. The mean event intensities are underestimated by about $0.15 \mathrm{~mm} / \mathrm{h}(25 \%)$ for all stations. The number of events generated by the Poisson model is in good agreement with the observations with a relative error of less than $1 \%$ (Tab. A.8).

\subsubsection{Intensity-frequency relationships (entire time series)}

The dry ratio which is approximately $90 \%$ in the observed data on average of all stations is slightly underestimated by the coupled Poisson and cascade model by $3 \%$ on average (Tab. A.9). While the observed data contain about $2.7 \%$ intervals with intensities between $>0 \mathrm{~mm} / \mathrm{h}$ and $\leq 0.1$ 
$\mathrm{mm} / \mathrm{h}$, the coupled Poisson and cascade model generates around $5 \%$ intervals in that range (relative error: $90 \%$ ). Altogether, the number of intervals $\leq 0.1$ $\mathrm{mm} / \mathrm{h}$ is in good agreement between observations and the coupled model the relative error is less than $1 \%$ for all stations with a slight overestimation in case of Lindenberg and München-Flughafen and underestimation for the other stations. The fraction of intervals $>0.1 \mathrm{~mm} / \mathrm{h}$ and $\leq 10 \mathrm{~mm} / \mathrm{h}$ is well represented by the model with a mean relative error between $-3 \%$ and $5 \%$. The model tends to overestimate the fraction of intervals with intensities more than $10 \mathrm{~mm} / \mathrm{h}$ by approximately $20 \%$ averaged over all stations. The mean intensities of wet intervals generated by the coupled Poisson and cascade model are averaged over all stations around $0.13 \mathrm{~mm} / \mathrm{h}$ or $17 \%$ lower than those of the observed data (Tab. A.10). Their standard deviations show a relative error of approximately $2 \%$ and the skewness generated by the model is on average around $12 \%$ lower than that of the data. The model underestimates the median intensity of wet intervals by around $50 \%$.

The return periods of extreme hourly values are shown in Tab. A.11. The precipitation intensity with a return period of 0.5 years ranges between 9.9 $\mathrm{mm} / \mathrm{h}$ (Meiningen) and $12.7 \mathrm{~mm} / \mathrm{h}$ (Köln-Bonn), this value is reproduced by the coupled model with an average relative error of $5 \%$ whereby it is overestimated for all stations except for München-Flughafen. The observed data show precipitation intensities with a return period of 1.0 year between $13.5 \mathrm{~mm} / \mathrm{h}$ (Meiningen) and $18.1 \mathrm{~mm} / \mathrm{h}$ (München-Flughafen), based on the medians of 60 realisations the model shows relative errors of less than \pm 
$10 \%$ (averaged over all stations: -2 \%). Observed precipitation intensities with a return period of 2.0 years are between $15.8 \mathrm{~mm} / \mathrm{h}$ (Meiningen) and $24.4 \mathrm{~mm} / \mathrm{h}$ (München-Flughafen), the model reproduces these values with a relative error of on average $-5 \%$. Precipitation intensities with a return period of 5.6 years and 12.6 years tend to be overestimated by the model by on average $5 \%$ with stronger deviations for individual stations. Table A.12 shows the return period of daily extreme values.

Daily precipitation intensities with a return period of 0.5 years range from $20.9 \mathrm{~mm} / \mathrm{d}$ to $30.0 \mathrm{~mm} / \mathrm{d}$, these values are generally overestimated by the coupled model by on average $20 \%$. The model results furthermore show a slightly too high daily precipitation with return period of 1 year and 2 years for all stations (average $15 \%$ ). In terms of daily precipitation intensities with a return period of 5.6 years and 12.6 the model shows both positive and negative deviations from the observed data depending on the station. On average precipitation intensities with a return period of 5.6 years are overestimated by $7 \%$ and precipitation intensities with a return period of 12.6 years are underestimated by $6 \%$. Here, the very high observed precipitation intensity at Rostock-Warnemünde has to be noted.

\subsubsection{Temporal pattern (entire time series)}

The coupled Poisson and cascade model produces about $20 \%$ longer mean dry spell durations (length of consecutive dry intervals) than the observed data, their standard deviation is well reflected by the model with a relative 
error of approximately $-8 \%$ and their skewness is underestimated by about $40 \%$ (Tab. A.13). On average, the model results in about $50 \%$ longer mean wet spell durations (length of consecutive wet intervals), their standard deviations are around $15 \%$ too high and their skewness around $40 \%$ too low compared to the observed data.

Both Spearman's rank autocorrelation and Pearson's autocorrelation are relatively well reproduced by the coupled Poisson and cascade model up to a lag time of $8 \mathrm{~h}$ as shown for the station Lindenberg in Fig. 6 and for all stations in Tab. A.14. Averaged over all stations, Spearman's rank autocorrelation is overestimated by $20 \%$ for a lag time of $1 \mathrm{~h}, 17 \%$ for a lag time of $3 \mathrm{~h}$ and $4 \mathrm{~h}$, and $8 \%$ for a lag time of 9 hours. Pearsons's autocorrelation is slightly overestimated by about $12 \%$ for these lag times. For longer lag times, the autocorrelation is underestimated in case of the stations Cottbus, Lindenberg, Meiningen and München-Flughafen and overestimated for the other stations (not shown here).

\section{Discussion}

\subsection{Model parameterisation}

The coupled Poisson and constrained cascade model is able to capture location-specific precipitation characteristics in terms of dry periods, precipitation events, and within-event variability as all model parameters are directly estimated from the data. A critical aspect is the ambiguity in the definition of independent precipitation events (Acreman, 1990; Molina-Sanchis 

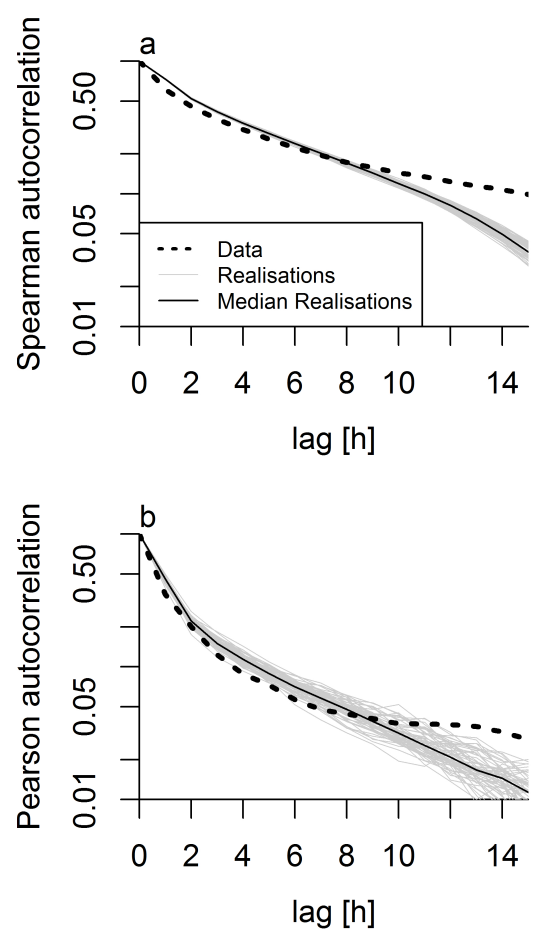

Figure 6: Autocorrelation of observed data and of the coupled Poisson and cascade model for the station Lindenberg. a) Spearman's rank autocorrelation. b) Pearson's autocorrelation. 
et al., 2016; Langousis and Veneziano, 2007). Different approaches to estimate the minimum time between independent precipitation events result in values ranging from few minutes to days (e.g. Restrepo-Posada and Eagleson, 1982; Schilling, 1984; Heneker et al., 2001; Medina-Cobo et al., 2016; Djallel Dilmi et al., 2017). Therefore, the influence of the minimum dry period on the model performance requires further testing especially when considering sub-hourly precipitation data. The choice of the minimum dry period duration might depend on the requirements on generated precipitation time series for the application of interest.

We found pronounced scale dependence for the cascade model, both the probabilities of the multiplicative weights and the parameter $H$ which expresses the scale dependence of the parameter $a$ used in the symmetrical beta distribution of the weights in the $\mathrm{x} /(1-\mathrm{x})$-splitting. The probabilities of (0/1)-splitting of all stations increase with scale (level of aggregation from fine to coarse resolution) in case of the enclosed and ending position classes, whereas the probabilities of (1/0)-splitting increase for the enclosed and starting position classes. Increasing probabilities of (0/1)-splitting for the ending position class and for (1/0)-splitting for the starting class have also been shown by Olsson (1998) for Swedish stations for timescales up to 34 hours and by McIntyre et al. (2016) for timescales up to one day. However, both Olsson (1998) and Güntner et al. (2001) showed scale invariance for the probabilities of multiplicative weights for the enclosed position class for Swedish, British and Brazilian stations for timescales between 1 hour and 32 hours. The 
parameterisation of the cascade model is very similar between the different stations as expressed by the probabilities of the multiplicative weights $\left(P_{\infty}\right.$ for $t=\infty$ and direction of change with scale) for 0/1-splitting, 1/0-splitting and $\mathrm{x} /(1-\mathrm{x})$-splitting. The probabilities of the multiplicative weights at $P_{\infty}$ furthermore approximately lie in the ranges derived by Güntner et al. (2001) and Müller (2016) for Brazilian, British and German stations for resolutions between 1-32 hours for the respective position and volume classes. The sigmoid functions allow considering the temporal scaling of the probabilities of multiplicative weights for different event durations. However, these functions do not ensure that the sum of the probabilities for $\mathrm{P}(0 / 1), \mathrm{P}(1 / 0)$ and $\mathrm{P}(\mathrm{x} /(1-\mathrm{x})$ is always 1.0 , but slight deviations may occur for some disaggregation time steps.

We found that the parameter $a$ which describes the multiplicative weights in case of the $\mathrm{x} /(1-\mathrm{x})$-splitting decreases with timescale, which is consistent with other studies (e.g. Licznar et al., 2011a; Molnar and Burlando, 2005; Rupp et al., 2009). Licznar et al. (2011a) noted that values of the parameter $H$ which expresses the scale dependence of the parameter $a$ range between 0.45 and 0.55 for various studies considering different timescale ranges and climate types (e.g. 0.454 (Licznar et al., 2011a), 0.455 (Molnar and Burlando, 2005), 0.47 (Menabde and Sivapalan, 2000), 0.478 (Rupp et al., 2009), 0.531 (Paulson and Baxter, 2007)). These studies did not specify the parameter $H$ for individual position and volume classes and thus the parameters $H$ are not directly comparable to the values obtained in our study, in which both 
position and volume classes are considered for the temporal scaling of the parameter $a$. However, it has to be noted that we found $H$ parameters ranging between 0.4 and 0.5 in case of the enclosed above, ending below and isolated below position and volume classes (all stations) and for four stations also in case of the enclosed below class. A similarity of disaggregation parameters across climatic regions has also been found by Heneker et al. (2001) for the Australian stations Brisbane, Melbourne and Sydney. This implies a general scaling behavior of precipitation and indicates that the cascade model parameters can be regionalised for the disaggregation of precipitation. However, it has to be noted that Molnar and Burlando (2008) found both regional and seasonal differences in scaling behavior due to orographic influence and snowfall which would have to be considered in regionalisation approaches.

In agreement with findings from cascade model applications for Germany, Brazil, Great Britain and Sweden (e.g. Müller, 2016; Güntner et al., 2001; Olsson, 1998) seasonality did not influence the model parameterisation of the stations selected. For applications of the coupled Poisson and constrained cascade model to regions with higher seasonal influence, the seasonal dependence of the model parameters needs to be considered as shown by Hipsey et al. (2003) for the Poisson model and by Molnar and Burlando (2008) for the MCR model. Similarly, if the model parameters exhibit decadal variations as reported by McIntyre et al. (2016) for Brisbane, these can be included. Maintaining diurnal patterns in the stochastic generation of precipitation time series would, however, require a modification of the model structure of 
the Poisson model with explicit consideration of time of day and a daytime specific parameterisation of the cascade model.

\subsection{Evaluation of disaggregation approaches}

The constrained MRC model developed in this study to disaggregate precipitation events combines aspects of the MRC models proposed by Olsson (1998) and Menabde and Sivapalan (2000) and was thus able to overcome inconsistencies in the temporal structure of the Poisson and MRC models. Differences between the time series generated by the MRC models are most pronounced in terms of event characteristics and consequently in terms of the temporal pattern of the entire time series.

Cascade model C1 has been developed by Olsson (1998) to disaggregate daily precipitation and thus is not aimed at conserving precipitation events. The model tends to allocate precipitation to the centre of the event as 0/1-, $1 / 0$ - and $\mathrm{x} /(1-\mathrm{x})$-splitting are allowed irrespective of the position of an interval within an event. Thus, when applied to disaggregate precipitation events this model generally underestimates event durations and accordingly overestimates the dry ratio both within events and in the entire time series. On the other hand, dry spell durations are overestimated when two consecutive events are shortened by this cascade model. The autocorrelation is underestimated by this cascade model as noticed in many studies where it is employed to disaggregate daily precipitation (Güntner et al., 2001; Müller and Haberlandt, 2018; Förster et al., 2016; Paschalis et al., 2014). This can 
be explained by the sequence of dry and wet intervals as visible from the autocorrelation for binarized timeseries.

Cascade model C2 developed by Menabde and Sivapalan (2000), which conserves precipitation events by accounting for $\mathrm{x} /(1-\mathrm{x})$-splitting only, does not reproduce intra-event intermittency. However, intermittency is an important characteristic of precipitation events as the observed data show a mean event dry ratio of around $30 \%$ which increases with event duration. For numerical reasons a small fraction of dry intervals within events (less than 1\%) is obtained when very small intensities below the smallest positive double of the machine (usually about 5e-324) are estimated from the $\mathrm{x} /(1-\mathrm{x})$-splitting. Hence, the dry spell durations are equal to the dry period durations and the wet spell durations are equal to the event durations. Due to lacking intraevent intermittency, the dry ratio in the entire time series is underestimated by $15 \%$, while the model generates around $10 \%$ intervals of precipitation intensity $<0.1 \mathrm{~mm} / \mathrm{h}$. This cascade model tends to distribute precipitation almost uniformly among the intervals of the event. The autocorrelation in the precipitation time series generated by this model is higher than that of the observed data as all intervals within the event are considered as wet and as the autocorrelation is dominated by the sequence of dry and wet intervals. Spearman's rank autocorrelation does not differ for the realisations as these are based on the same events as event durations are strictly conserved by this model.

The constrained cascade model, C3, developed in this study combines the 
characteristics of the cascade models C1 developed by Olsson (1998) which allows for intra-event intermittency by allowing (0/1)-, (1/0) and x/(1-x)splitting, and C2 by Menabde and Sivapalan (2000) which preserves event durations by allowing $\mathrm{x} /(1-\mathrm{x})$-splitting only. This is realized by constraining the branching of the first interval of a precipitation event to $(1 / 0)$ and $\mathrm{x} /(1-$ $\mathrm{x})$-splitting and the branching of the last interval of a precipitation event to $(0 / 1)$ and $\mathrm{x} /(1-\mathrm{x})$-splitting at each level of disaggregation. That way, the constrained cascade is able to better reproduce both intra-event intermittency and within-storm intensity fluctuations compared to the cascade models C1 and $\mathrm{C} 2$. Accordingly, also the constrained cascade model mimics the temporal pattern of the entire time observed time series. The autocorrelation as an integrative metric of the temporal pattern of the precipitation time series is conserved by the constrained cascade model up to approximately $6 \mathrm{~h}$ which corresponds to typical wet spell durations, i.e. the sum of the mean wet spell duration and the standard duration of the wet spell duration.

The time series generated by the three cascade models furthermore differ with respect to intensity-frequency relationships. The cascade models $\mathrm{C} 2$ and C3 result in many intervals with very low intensities $\leq 0.1 \mathrm{~mm} / \mathrm{h}$ (on average: C2: $54 \%$ of all wet intervals, C3: $31 \%$ of all wet intervals compared to 26 $\%$ in the observations). An overestimation of the number of precipitation intervals with very small intensities is common to MRC models as shown by Molnar and Burlando (2005), Müller and Haberlandt (2018) and Garbrecht et al. (2017). As the dry ratio of C3 is in good agreement with the observed 
data, this model also shows a comparably good performance in terms of the intensities of wet intervals (mean, standard deviation, skewness) and the ratio of intensities between $>0.1 \mathrm{~mm} / \mathrm{h}$ and $\leq 10 \mathrm{~mm} / \mathrm{h}$.

The three cascade models used are very consistent in terms of the generated temporal pattern, the different realisations in terms of the criteria used to characterize the temporal pattern of the entire time series (not shown here).

\subsection{General performance of the coupled Poisson and cascade model}

To assess the general performance of the coupled model in the absence of a standard for evaluating stochastic precipitation models we followed the categorization by Garbrecht et al. (2017). That means absolute values of relative errors between 0 to $20 \%$ are classified as 'adequate or good'. Accordingly, the coupled poisson and MRC model performs adequately in terms of the Poisson model parameters obtained from the generated events (mean dry period duration, mean event duration), except for the mean event intensities which are underestimated by $25 \%$ due to the high number of intervals with very low intensities. In terms of intensity-frequency relationships of the entire time series, the dry ratio, the total fraction of intervals $\leq 0.1 \mathrm{~mm} / \mathrm{h}$ (including both dry intervals and intervals with very low intensities), the fraction of intervals $\geq 0.1 \mathrm{~mm} / \mathrm{h}$ and $\leq 10 \mathrm{~mm} / \mathrm{h}$, and the fraction of intervals $\geq 10 \mathrm{~mm} / \mathrm{h}$ are reproduced adequately. Compared to the disaggregation of observed events the coupled model further overestimates the number of 
intervals with very low intensities $>0 \mathrm{~mm} / \mathrm{h}$ and $\leq 0.1 \mathrm{~mm} / \mathrm{h}$ (on average: $40 \%$ of wet intervals compared to $31 \%$ when disaggregating events using cascade model $\mathrm{C} 3$ and around $26 \%$ in the observations). The generation of mean event intensities from Gamma distributions for storm duration classes results in a pronounced number of long events with low mean event intensities. When these events are disaggregated to hourly precipitation, this is propagated by the cascade model so that many intervals with very low intensities $\leq 0.1 \mathrm{~mm} / \mathrm{h}$ are obtained. Due to the measurement accuracy, intervals $<0.1 \mathrm{~mm} / \mathrm{h}$ can not be observed by conventional tipping bucket rain gauges. As shown from radar measurements by Peters and Christensen (2002) such small precipitation intensities do occur in reality. The measurement accuracy of $0.1 \mathrm{~mm} / \mathrm{h}$ in turn affects the parameterisation of the coupled model, according to Licznar et al. (2011b) this is especially the case for the beta distributions used in the $\mathrm{x} /(1-\mathrm{x})$-splitting. The model performance of the intensities of wet intervals is adequate in terms of mean, standard deviation and skewness. The median intensity of wet intervals is underestimated due to the high proportion of very low intensities. While moderate precipitation intensities in both hourly and daily resolution are generally well reproduced by the coupled Poisson and constrained cascade model, the model tends to overestimate heavy precipitation at the hourly timescale. One reason might be that the relatively short precipitation records (20 years), which were used for the model parameterisation, do not include enough heavy precipitation intervals. This has been reported by Furrer and Katz (2008) as a general 
problem of parametric weather generators. Furthermore, as pointed out by Ramesh et al. (2017), most stochastic precipitation models are having difficulties in reproducing extreme values at high temporal resolutions. One of the reasons is that relatively few intervals with high intensities are included in precipitation records (Garbrecht et al., 2017). As daily precipitation intensities are not considered in the model parameterisation, the model does not perform better at daily than at hourly scale.

The coupled model overcomes the limitation of MRC models in terms of an underestimation of temporal autocorrelation for small lag times, which occurs in various studies (e.g. Paschalis et al., 2014; Müller and Haberlandt, 2018). The representation of dry spell durations by the coupled model is adequate, whereas too long wet spell durations are generated.

Overall, the coupled Poisson and constrained MRC model preserves the temporal pattern of precipitation both in terms of consecutive precipitation events and dry periods as well as within-storm patterns and furthermore daily values. Thus it fulfills the requirements set by Lombardo et al. (2012) and Paschalis et al. (2014) that generated precipitation time series should preserve the statistics of observations both at fine and coarse resolution. The shortcoming of the Poisson and multiplicative random cascade models of not being able to perform robust simulation across temporal scales as expressed by Paschalis et al. (2014) has been overcome by the coupled Poisson and constrained cascade model. This corresponds to the results by Paschalis et al. (2014) who showed that a good performance of rainfall models at multiple 
scales requires multiple approaches as they found a better performance for coupled Poisson and cascade as well as coupled Markov chain and cascade models compared to the individual models respectively.

\section{Summary and Outlook}

A coupling approach between Poisson rectangular pulse and MRC models has been developed which overcomes the inconsistency between the temporal structures in these models. This has been realized by (a) a modified cascade approach ("constrained cascade") which conserves event durations, and (b) continuous functions of the multiplicative weights to consider the timescaledependency in the disaggregation of events with different durations. The constrained cascade model combines elements of the cascade models by Olsson (1998) and Menabde and Sivapalan (2000). The advantage of the coupled Poisson rectangular pulse and constrained cascade model is the more realistic representation of the temporal pattern of precipitation time series (dry and wet spell durations, autocorrelation), intra-event intermittency and withinstorm variability compared to applying the cascade models by Olsson (1998) and Menabde and Sivapalan (2000) to event-based precipitation.

Even though autocorrelation is not explicitly considered in the model parameterisation, it is mimicked well in timescales which correspond to typical wet spell durations. An additional improvement of the autocorrelation for longer time spans might be achieved by applying a resampling algorithm (e.g. simulated annealing, Bárdossy (1998)) to swap the events generated by the 
Poisson model or by the application of a dyadic cascade model approach (e.g. Lombardo et al., 2012). The model does not explicitly consider influences of precipitation event durations and mean event intensities on their disaggregation. However, as shown by Veneziano and Lepore (2012) within-storm scaling differs from scaling behaviour of the entire precipitation record. Explicitly including within-storm scaling in the parameterisation of the MRC model might further improve the representation of the temporal pattern of the precipitation time series.

Precipitation intensities are well reproduced in terms of moderate intensities at both the hourly timescale and the daily timescale. The overestimation of the fraction of small intensities below the data accuracy of $0.1 \mathrm{~mm}$ could be eliminated by post-processing of the model results. A better representation of heavy precipitation could be realised by using alternative distribution functions to generate mean event intensities and to disaggregate precipitation within events. In terms of mean event intensities more heavy-tailed distribution functions (such as the Levy-stable distribution used by Menabde and Sivapalan (2000)) or hybrid distribution functions as found advantageous by Furrer and Katz (2008) for daily precipitation might need to be explored. More realistic hourly intensities might be achieved by describing the cascade weights for $\mathrm{x} /(1-\mathrm{x})$-splitting by a combined distribution such as the $3 \mathrm{~N}-\mathrm{B}$ distribution (composite of three separate normal distributions and one beta distribution) as shown by Licznar et al. (2011b) and Licznar et al. (2015). Our coupled Poisson and constrained cascade model represents a method- 
ological advancement towards a more realistic representation of temporal patterns in stochastic precipitation models. The model presented here can be used to generate synthetic time series as inputs for Monte Carlo simulations of processes for which an hourly resolution is sufficient, e.g. for hydrological processes at the catchment scale (e.g. Sikorska and Seibert, 2018). Further development will focus on better representing precipitation intensities at high temporal resolution to assess statistical properties of fast hydrological processes which are significantly influenced by within-storm variability.

\section{Acknowledgements}

Hourly precipitation data have been obtained from the German Weather Service (DWD). We thank Paweł Licznar and David Dunkerley and the associate editor Andreas Langousis for their valuable comments and constructive suggestions. We are grateful to Daniel Caviedes-Voullième for the fruitful discussion and comments on an earlier version of the manuscript. This research did not receive any specific grant from funding agencies in the public, commercial, or not-for-profit sectors.

\section{References}

Acreman, M.G., 1990. A simple stochastic model of hourly rainfall for Farnborough, England. Hydrological Sciences Journal-Journal Des Sciences Hydrologiques 352, 119-148. 
Adyel, T.M., Oldham, C.E., Hipsey, M.R., 2017. Storm event-scale nutrient attenuation in constructed wetlands experiencing a Mediterranean climate: A comparison of a surface flow and hybrid surface-subsurface flow system. Science of the Total Environment 598, 1001-1014.

Bárdossy, A., 1998. Generating precipitation time series using simulated annealing. Water Resources Research 34, 1737-1744.

Berndtsson, R., Niemczynowicz, J., 1988. Spatial and temporal scales in rainfall analysis - some aspects and future perspectives. Journal of Hydrology 100, 293-313.

Berne, A., Delrieu, G., Creutin, J.D., Obled, C., 2004. Temporal and spatial resolution of rainfall measurements required for urban hydrology. Journal of Hydrology 299, 166-179.

Bonta, J.V., 2004. Stochastic simulation of storm occurrence, depth, duration and within-storm intensities. Transactions of the ASAE 47, 1573-1584.

Bonta, J.V., Rao, A.R., 1988. Factors affecting the identification of independent storm events. Journal of Hydrology 98, 275-293.

Borris, M., Viklander, M., Gustafsson, A.M., Marsalek, J., 2014. Modelling the effects of changes in rainfall event characteristics on TSS loads in urban runoff. Hydrological Processes 28, 1787-1796.

Ding, J., Wallner, M., Müller, H., Haberlandt, U., 2016. Estimation of 
instantaneous peak flows from maximum mean daily flows using the HBV hydrological model. Hydrological Processes 1448, 1431-1448.

Djallel Dilmi, M., Mallet, C., Barthes, L., Chazottes, A., 2017. Data-driven clustering of rain events: Microphysics information derived from macroscale observations. Atmospheric Measurement Techniques 10, 1557-1574.

Dolšak, D., Bezak, N., Šraj, M., 2016. Temporal characteristics of rainfall events under three climate types in Slovenia. Journal of Hydrology 541, 1395-1405.

Dunkerley, D., 2008. Rain event properties in nature and in rainfall simulation experiments: A comparative review with recommendations for increasingly systematic study and reporting. Hydrological Processes 22, 4415-4435.

Dunkerley, D., 2012. Effects of rainfall intensity fluctuations on infiltration and runoff: Rainfall simulation on dryland soils, Fowlers Gap, Australia. Hydrological Processes 26, 2211-2224.

Dunkerley, D., 2014. Stemflow on the woody parts of plants: Dependence on rainfall intensity and event profile from laboratory simulations. Hydrological Processes 28, 5469-5482.

Dunkerley, D., 2015. Intra-event intermittency of rainfall: an analysis of the metrics of rain and no-rain periods. Hydrological Processes 29, 3294-3305. 
DWA-A 531, 2012. Starkregen in Abhängigkeit von Wiederkehrzeit und Dauer. Technical Report. Arbeitsblatt der DWA, Hennef.

Emmanuel, I., Andrieu, H., Leblois, E., Flahaut, B., 2012. Temporal and spatial variability of rainfall at the urban hydrological scale. Journal of Hydrology 430-431, 162-172.

Fatichi, S., Ivanov, V.Y., Caporali, E., 2011. Simulation of future climate scenarios with a weather generator. Advances in Water Resources 34, 448467.

Fiener, P., Neuhaus, P., Botschek, J., 2013. Long-term trends in rainfall erosivity-analysis of high resolution precipitation time series (1937-2007) from Western Germany. Agricultural and Forest Meteorology 171-172, $115-123$.

Förster, K., Hanzer, F., Winter, B., Marke, T., Strasser, U., 2016. An open-source MEteoroLOgical observation time series DISaggregation Tool (MELODIST v0.1.1). Geoscientific Model Development 9, 2315-2333.

Furrer, E.M., Katz, R.W., 2008. Improving the simulation of extreme precipitation events by stochastic weather generators. Water Resources Research $44,1-13$.

Garbrecht, J.D., Gyawali, R., Malone, R.W., Zhang, J.C., 2017. Cascade Rainfall Disaggregation Application in U . S . Central Plains. Environment and Natural Resources Research 7, 30-43. 
Güntner, A., Olsson, J., Calver, A., Gannon, B., 2001. Cascade-based disaggregation of continuous rainfall time series: the influence of climate. Hydrology and Earth System Sciences 5, 145-164.

Gyasi-Agyei, Y., 2011. Copula-based daily rainfall disaggregation model. Water Resources Research 47, 1-17.

Haberlandt, U., Ebner von Eschenbach, A.D., Buchwald, I., 2008. A spacetime hybrid hourly rainfall model for derived flood frequency analysis. Hydrology and Earth System Sciences 12, 1353-1367.

Hearman, A.J., Hinz, C., 2007. Sensitivity of point scale surface runoff predictions to rainfall resolution. Hydrology and Earth System Sciences 11, 965-982.

Heneker, T.M., Lambert, M.F., Kuczera, G., 2001. A point rainfall model for risk-based design. Journal of Hydrology 247, 54-71.

Hipsey, M.R., Sivapalan, M., Menabde, M., 2003. A risk-based approach to the design of rural water supply catchments across Western Australia. Hydrological Sciences Journal 48, 709-727.

Huxman, T.E., Snyder, K.A., Tissue, D., Leffler, A.J., Ogle, K., Pockman, W.T., Sandquist, D.R., Potts, D.L., Schwinning, S., 2004. Precipitation pulses and carbon fluxes in semiarid and arid ecosystems. Oecologia 141, $254-268$. 
Jothityangkoon, C., Sivapalan, M., 2001. Temporal scales of rainfallrunoff processes and spatial scaling of flood peaks: Space-time connection through catchment water balance. Advances in Water Resources 24, $1015-1036$.

Knapp, A.K., Fay, P.A., Blair, J.M., Collins, S.L., Smith, M.D., Carlisle, J.D., Harper, C.W., Danner, B.T., Lett, M.S., Mccarron, J.K., 2002. Rainfall Variability, Carbon Cycling, and Plant Species Diversity in a Mesic Grassland. Science 298, 2202-2206.

Kossieris, P., Makropoulos, C., Onof, C., Koutsoyiannis, D., 2016. A rainfall disaggregation scheme for sub-hourly time scales: Coupling a BartlettLewis based model with adjusting procedures. Journal of Hydrology .

Koutsoyiannis, D., 2001. Coupling stochastic models of different time scales. Water Resources Research 37, 379-392.

Koutsoyiannis, D., Onof, C., Wheater, H.S., 2003. Multivariate rainfall disaggregation at a fine timescale. Water Resources Research 39, 1-62. 1512.00567.

Kusumastuti, D.I., Struthers, I., Sivapalan, M., Reynolds, D.A., 2007. Threshold effects in catchment storm response and the occurrence and magnitude of flood events : implications for flood frequency. Hydrology and Earth System Sciences 11, 1515-1528. 
Langousis, A., Veneziano, D., 2007. Intensity-duration-frequency curves from scaling representations of rainfall. Water Resources Research 43, 1-12.

Licznar, P., De Michele, C., Adamowski, W., 2015. Precipitation variability within an urban monitoring network via microcanonical cascade generators. Hydrology and Earth System Sciences 19, 485-506.

Licznar, P., Łomotowski, J., Rupp, D.E., 2011a. Random cascade driven rainfall disaggregation for urban hydrology: An evaluation of six models and a new generator. Atmospheric Research 99, 563-578.

Licznar, P., Schmitt, T., Rupp, D., 2011b. Distributions of microcanonical cascade weights of rainfall at small timescales. Acta Geophysica 59, 10131043.

Lombardo, F., Volpi, E., Koutsoyiannis, D., 2012. Rainfall downscaling in time: theoretical and empirical comparison between multifractal and Hurst-Kolmogorov discrete random cascades. Hydrological Sciences Journal-Journal Des Sciences Hydrologiques 57, 1052-1066.

Lombardo, F., Volpi, E., Koutsoyiannis, D., Serinaldi, F., 2017. A theoretically consistent stochastic cascade for temporal disaggregation of intermittent rainfall. Water Resources Research 53, 4586-4605. 2014 WR016527.

Mandapaka, P.V., Krajewski, W.F., Mantilla, R., Gupta, V.K., 2009. Advances in Water Resources Dissecting the effect of rainfall variability on 
the statistical structure of peak flows. Advances in Water Resources 32, 1508-1525.

McGrath, G., Hinz, C., Sivapalan, M., 2010. Assessing the impact of regional rainfall variability on rapid pesticide leaching potential. Journal of Contaminant Hydrology 113, 56-65.

McGrath, G.S., Hinz, C., Sivapalan, M., 2008. Modelling the impact of within-storm variability of rainfall on the loading of solutes to preferential flow pathways. European Journal of Operational Research 59, 24-33.

McIntyre, N., Shi, M., Onof, C., 2016. Incorporating parameter dependencies into temporal downscaling of extreme rainfall using a random cascade approach. Journal of Hydrology 542, 896-912.

Medina-Cobo, M.T., García-Marín, A., Estévez, J., Ayuso-Muñoz, J., 2016. The identification of an appropriate Minimum Inter-event Time (MIT) based on multifractal characterization of rainfall data series. Hydrological Processes 30, 3507-3517.

Menabde, M., Sivapalan, M., 2000. Modeling of rainfall time series and extremes using bounded random cascades and levy-stable distributions. Water Resources Research 36, 3293.

Molina-Sanchis, I., Lázaro, R., Arnau-Rosalén, E., Calvo-Cases, A., 2016. Rainfall timing and runoff: The influence of the criterion for rain event separation. Journal of Hydrology and Hydromechanics 64, 226-236. 
Molini, A., Katul, G.G., Porporato, A., 2010. Scale wise evolution of rainfall probability density functions fingerprints the rainfall generation mechanism. Geophysical Research Letters 37, 1-5.

Molini, A., La Barbera, P., Lanza, L.G., Stagi, L., 2001. Rainfall Intermittency and the Sampling Error of Tipping-Bucket Rain Gauges. Physics and Chemistry of the Earth (C) 26, 737-742.

Molnar, P., Burlando, P., 2005. Preservation of rainfall properties in stochastic disaggregation by a simple random cascade model. Atmospheric Research $77,137-151$.

Molnar, P., Burlando, P., 2008. Variability in the scale properties of highresolution precipitation data in the Alpine climate of. Water Resources Research 44, 1-9.

Müller, H., 2016. Niederschlagsdisaggregation für hydrologische Modellierung - Mitteilungen des Instituts für Waserwirtschaft, Hydrologie und landwirtschaftlichen Wasserbau, 101, ISSN 0343-8090. Dissertation. Leibniz Universität Hannover.

Müller, H., Haberlandt, U., 2015. Temporal rainfall disaggregation with a cascade model: from single-station disaggregation to spatial rainfall. Journal of Hydrologic Engineering 20.

Müller, H., Haberlandt, U., 2018. Temporal rainfall disaggregation using a 
multiplicative cascade model for spatial application in urban hydrology. Journal of Hydrology 556, 847-864.

Nel, W., Hauptfleisch, A., Sumner, P.D., Boojhawon, R., Rughooputh, S.D.D.V., Dhurmea, K.R., 2016. Intra-event characteristics of extreme erosive rainfall on Mauritius. Physical Geography 37, 264-275.

Olsson, J., 1998. Evaluation of a scaling cascade model for temporal rainfall disaggregation. Hydrology and Earth System Sciences 2, 19-30.

Onof, C., Wheater, H.S., 1993. Modelling of British rainfall using a random parameter Bartlett-Lewis rectangular pulse model. Journal of Hydrology $149,67-95$.

Parmesan, C., Root, T.L., Willig, M.R., 2000. Impacts of extreme weather and climate on terrestiral biota. Bulletin of the American Meteorological Society $81,443-450$.

Paschalis, A., Molnar, P., Fatichi, S., Burlando, P., 2014. On temporal stochastic modeling of precipitation, nesting models across scales. Advances in Water Resources 63, 152-166.

Paulson, K.S., Baxter, P.D., 2007. Downscaling of rain gauge time series by multiplicative beta cascade. Journal of Geophysical Research Atmospheres $112,1-8$.

Peel, M.C., Finlayson, B.L., McMahon, T.A., 2007. Updated world map of 
the Köppen-Geiger climate classification. Hydrology and Earth System Sciences 11, 1633-1644. hal-00298818.

Peters, O., Christensen, K., 2002. Rain: Relaxations in the sky. Physical Review E - Statistical, Nonlinear, and Soft Matter Physics 66, 1-9. 0204109.

Pui, A., Sharma, A., Mehrotra, R., Sivakumar, B., Jeremiah, E., 2012. A comparison of alternatives for daily to sub-daily rainfall disaggregation. Journal of Hydrology 470-471, 138-157.

R Core Team, 2016. R: A Language and Environment for Statistical Computing.

Ramesh, N.I., Garthwaite, A.P., Onof, C., 2017. A doubly stochastic rainfall model with exponentially decaying pulses. Stochastic Environmental Research and Risk Assessment .

Restrepo-Posada, P.J., Eagleson, P.S., 1982. Identification of independent rainstorms. Journal of Hydrology 55, 303-319.

Robinson, J.S., Sivapalan, M., 1997. Temporal scales and hydrological regimes: Implications for flood frequency scaling. Water Resources Research 33, 2981.

Rodriguez-Iturbe, I., Cox, D.R., Isham, V., 1987. Some Models for Rainfall Based on Stochastic Point Processes. Proceedings of the Royal Society A: Mathematical, Physical and Engineering Sciences 410, 269-288. 
Rupp, D.E., Keim, R.F., Ossiander, M., Brugnach, M., Selker, J.S., 2009. Time scale and intensity dependency in multiplicative cascades for temporal rainfall disaggregation. Water Resources Research 45, 1-14.

Samuel, J.M., Sivapalan, M., 2008. Effects of multiscale rainfall variability on flood frequency: Comparative multisite analysis of dominant runoff processes. Water Resources Research 44, 1-15.

Schertzer, D., Lovejoy, S., 1987. Physical modeling and analysis of rain and clouds by anisotropic scaling of multiplicative processes. Journal of Geophysical Research 92, 9963-971.

Schertzer, D., Lovejoy, S., 2011. Multifractals, Generalized Scale Invariance and Complexity in Geophysics. International Journal of Bifurcation and Chaos 21, 3417-3456.

Schilling, W., 1984. Univariate versus multivariate rainfall statistics - problems and potentials (a discussion). Water Science and Technology 16, $139-146$.

Schilling, W., 1991. Rainfall data for urban hydrology: what do we need? Atmospheric Research 27, 5-21.

Sikorska, A.E., Seibert, J., 2018. Appropriate temporal resolution of precipitation data for discharge modelling in pre-alpine catchments. Hydrological Sciences Journal 63, 1-16. 
Singh, V.P., 1997. Effect of spatial and temporal variability in rainfall and watershed characteristics on stream flow hydrograph. Hydrological Processes 11, 1649-1669.

Stedinger, J.R., Taylor, M.R., 1982. Synthetic streamflow generation: 1. Model verification and validation. Water Resources Research 18, 909-918.

Struthers, I., Hinz, C., Sivapalan, M., 2007. Conceptual examination of climate soil controls upon rainfall partitioning in an open-fractured soil II: Response to a population of storms. Advances in Water 30, 518-527.

Thober, S., Mai, J., Zink, M., Samaniego, L., 2014. Stochastic temporal disaggregation of monthly precipitation for regional gridded data sets. Water Resources Research 50, 8714-8735.

Van Stan, J.T., Elliot, L., Hildebrandt, A., Rebmann, C., Friesen, J., 2016. Impact of interacting bark structure and rainfall conditions on stemflow variability in a temperate beech-oak forest, central Germany. Hydrological Sciences Journal-Journal Des Sciences Hydrologiques 61, 2071-2083.

Veneziano, D., Langousis, A., 2010. Scaling and fractals in hydrology, in: Sivakumar, B., Berndtsson, R. (Eds.), Advances in data-based approaches for hydrologic modeling and forecasting. World Scientific. chapter 4, p. 145.

Veneziano, D., Langousis, A., Furcolo, P., 2006. Multifractality and rainfall extremes: A review. Water Resources Research 42, 1-18. 
${ }_{1117}$ Veneziano, D., Lepore, C., 2012. The scaling of temporal rainfall. Water ${ }_{1118}$ Resources Research 48, 1-16.

1119 Von Ruette, J., Lehmann, P., Or, D., 2014. Effects of rainfall spatial variabil${ }_{1120}$ ity and intermittency on shallow landslide triggering patterns at a catch${ }_{1121}$ ment scale. Water Resources Research 50, 7780-7799.

${ }_{1122}$ Weyhenmeyer, G.A., Willén, E., Sonesten, L., 2004. Effects of an extreme ${ }_{1123}$ precipitation event on water chemistry and phytoplankton in the Swedish $1124 \quad$ Lake Mälaren. Boreal Environment Research 9, 409-420.

${ }_{1125}$ Wiekenkamp, I., Huisman, J.A., Bogena, H.R., Lin, H.S., Vereecken, H., 1126 2016. Spatial and temporal occurrence of preferential flow in a forested ${ }_{1127}$ headwater catchment. Journal of Hydrology 534, 139-149. 

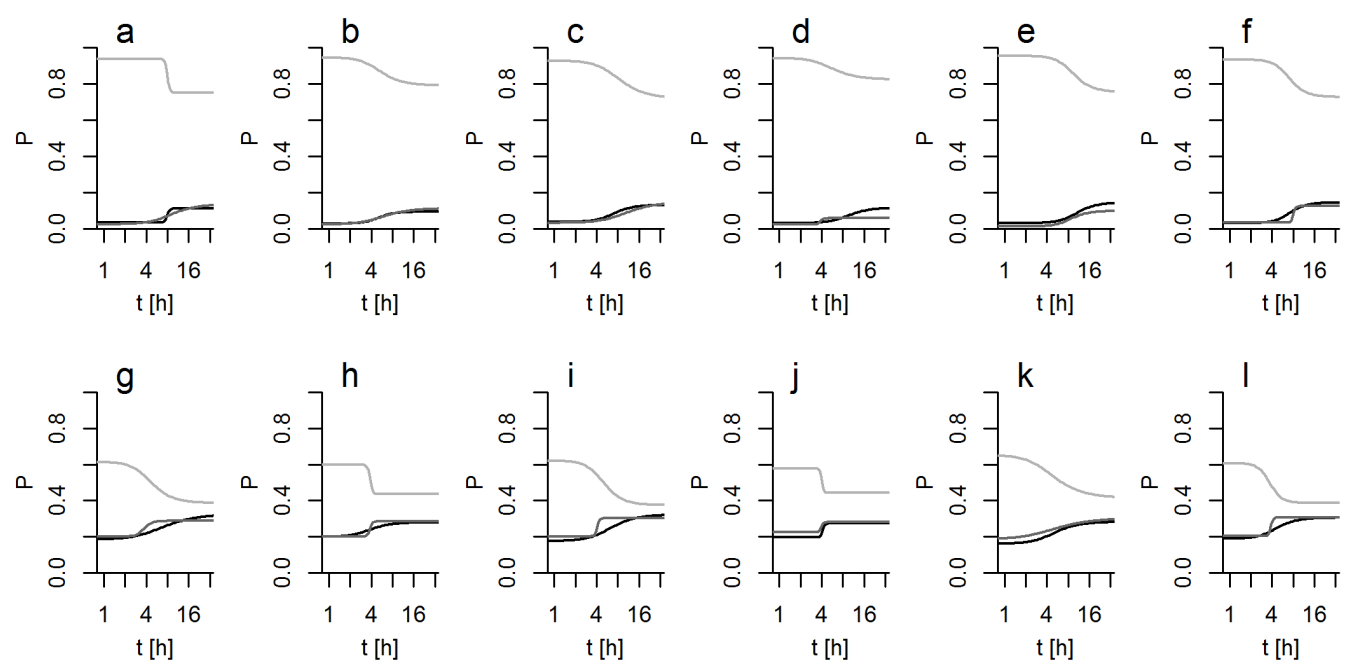

$P(0 / 1)$

$P(1 / 0) \quad \times P(x /(1-x))$

Figure A.1: Timescale dependent probabilities of the multiplicative weights at the example of the enclosed position class. Upper row: volume class above. a) Cottbus, b) Köln-Bonn, c) Lindenberg, d) Meiningen, e) München-Flughafen, f) Rostock-Warnemünde. Lower row: volume class below. g) Cottbus, h) Köln-Bonn, i) Lindenberg, j) Meiningen, k) München-Flughafen, l) Rostock-Warnemünde

\section{Appendix A. Results overview for all stations}

\section{List of changes}


Table 1: Criteria for model evaluation

\begin{tabular}{|c|c|}
\hline Criterion & Description \\
\hline \multicolumn{2}{|c|}{ Intensity-frequency relationship (entire time series) } \\
\hline Dry ratio $(\%)$ & $\begin{array}{l}\text { Number of intervals with intensity }=0 \mathrm{~mm} / \mathrm{h} \text { in } \\
\text { the time series versus total number of intervals in } \\
\text { the time series } * 100 \%\end{array}$ \\
\hline $\begin{array}{l}\text { Fraction of intervals }>0 \mathrm{~mm} / \mathrm{h} \text { and } \\
\leq 0.1 \mathrm{~mm} / \mathrm{h}(\%)\end{array}$ & $\begin{array}{l}\text { Number of intervals with intensity }>0 \mathrm{~mm} / \mathrm{h} \text { and } \\
\leq 0.1 \mathrm{~mm} / \mathrm{h} \text { in the time series versus total number } \\
\text { of intervals in the time series } * 100 \%\end{array}$ \\
\hline $\begin{array}{l}\text { Fraction of intervals }>0.1 \mathrm{~mm} / \mathrm{h} \text { and } \\
\leq 10 \mathrm{~mm} / \mathrm{h}(\%)\end{array}$ & $\begin{array}{l}\text { Number of intervals with intensity }>0.1 \mathrm{~mm} / \mathrm{h} \text { and } \\
\leq 10 \mathrm{~mm} / \mathrm{h} \text { in the time series versus total number } \\
\text { of intervals in the time series * } 100 \%\end{array}$ \\
\hline Fraction of intervals $>10 \mathrm{~mm} / \mathrm{h}(\%)$ & $\begin{array}{l}\text { Number of intervals with intensity }>10 \mathrm{~mm} / \mathrm{h} \text { in } \\
\text { the time series versus total number of intervals in } \\
\text { the time series } * 100 \%\end{array}$ \\
\hline Intensity of wet intervals $(\mathrm{mm} / \mathrm{h})$ & $\begin{array}{l}\text { Intensity of all intervals with intensity }>0 \mathrm{~mm} / \mathrm{h} \\
\text { in the time series }\end{array}$ \\
\hline \multicolumn{2}{|c|}{ Temporal pattern (entire time series) } \\
\hline Dry spell duration (h) & $\begin{array}{l}\text { Length of consecutive intervals with intensity } \\
=0 \mathrm{~mm} / \mathrm{h}\end{array}$ \\
\hline Wet spell duration $(\mathrm{h})$ & $\begin{array}{l}\text { Length of consecutive intervals with intensity } \\
>0 \mathrm{~mm} / \mathrm{h}\end{array}$ \\
\hline Autocorrelation () & $\begin{array}{l}\text { Autocorrelation function of the precipitation } \\
\text { depths }\end{array}$ \\
\hline \multicolumn{2}{|c|}{ Event characteristics } \\
\hline Event dry ratio (\%) & $\begin{array}{l}\text { Number of intervals with intensity }=0 \mathrm{~mm} / \mathrm{h} \text { in } \\
\text { the event versus event duration } * 100 \%\end{array}$ \\
\hline $\begin{array}{l}\text { Fraction of precipitation in quarters } \\
\text { of the event }(\%)\end{array}$ & $\begin{array}{l}\text { Precipitation depth in each quarter of the event } \\
\text { versus total event depth } * 100 \% \text { (calculated for } \\
\text { event durations of multiples of four) }\end{array}$ \\
\hline
\end{tabular}


Table 2: Details on the precipitation stations and climatic variables for 1996-2015

\begin{tabular}{|c|c|c|c|c|}
\hline Name & $\begin{array}{l}\text { Altitude } \\
(\mathrm{m})\end{array}$ & $\begin{array}{l}\text { Mean annual } \\
\text { precipitation } \\
(\mathrm{mm})\end{array}$ & $\begin{array}{l}\text { Mean annual } \\
\text { temperature } \\
\left({ }^{\circ} \mathrm{C}\right)\end{array}$ & Instrumentation \\
\hline Cottbus & 69 & 563 & 9.9 & $\begin{array}{l}\text { NG } 200(1996 \text { - 2008), } \\
\text { OTT PLUVIO (2008 - 2015) }\end{array}$ \\
\hline Köln-Bonn & 92 & 814 & 10.6 & $\begin{array}{l}\text { NG } 200(1996-2004), \\
\text { Joss-Tognini }(2004-2008), \\
\text { OTT PLUVIO }(2008-2015)\end{array}$ \\
\hline Lindenberg & 98 & 558 & 9.6 & $\begin{array}{l}\text { NG } 200(1996-2008) \\
\text { OTT PLUVIO (2008 - 2015) }\end{array}$ \\
\hline Meiningen & 450 & 661 & 8.3 & $\begin{array}{l}\text { NG } 200(1996-2008) \\
\text { OTT PLUVIO (2008 - 2015) }\end{array}$ \\
\hline $\begin{array}{l}\text { München- } \\
\text { Flughafen }\end{array}$ & 446 & 758 & 9.1 & $\begin{array}{l}\text { NG } 200(1996-2002) \\
\text { OTT PLUVIO (2002 - 2015) }\end{array}$ \\
\hline $\begin{array}{l}\text { Rostock- } \\
\text { Warnemünde }\end{array}$ & 4 & 624 & 9.7 & $\begin{array}{l}\text { NG } 200(1996-2008), \\
\text { OTT PLUVIO (2008 - 2015) }\end{array}$ \\
\hline
\end{tabular}

Table 3: Minimum dry period duration $d_{d, \min }$ and parameters of the Poisson rectangular pulse model: mean of the dry period durations $d_{d, \text { mean }}$, mean event duration $d_{e, \text { mean }}$, mean event intensity $i_{e, \text { mean }}$

\begin{tabular}{lllll}
\hline Station & $d_{d, \text { min }}(\mathrm{h})$ & $d_{d, \text { mean }}(\mathrm{h})$ & $d_{e, \text { mean }}(\mathrm{h})$ & $\begin{array}{l}i_{e, \text { mean }} \\
(\mathrm{mm} / \mathrm{h})\end{array}$ \\
\hline Cottbus & 17.8 & 71.1 & 18.5 & 0.47 \\
Köln-Bonn & 16.7 & 62.9 & 21.4 & 0.48 \\
Lindenberg & 17.4 & 71.4 & 17.3 & 0.50 \\
Meiningen & 16.5 & 66.8 & 21.6 & 0.43 \\
München-Flughafen & 14.0 & 65.4 & 16.7 & 0.55 \\
Rostock-Warnemünde & 21.6 & 74.7 & 23.6 & 0.44 \\
\hline
\end{tabular}


Table 4: Ranges of the probabilities of the multiplicative weights $P_{\infty}$ for $t=\infty$ based on all stations and indication of change with scale (level of aggregation from fine to coarse scale): increase $(\nearrow)$, decrease $(\searrow)$, no change or not consistent between stations $(\rightarrow)$.

\begin{tabular}{llll}
\hline Position and volume class & $0 / 1$-splitting & $1 / 0$-splitting & $\mathrm{x} /(1-\mathrm{x})$-splitting \\
\hline starting above & $0.21-0.34(\rightarrow)$ & $0.08-0.12(\nearrow)$ & $0.55-0.68(\searrow)$ \\
starting below & $0.49-0.58(\searrow)$ & $0.18-0.23(\nearrow)$ & $0.21-0.32(\rightarrow)$ \\
enclosed above & $0.09-0.15(\nearrow)$ & $0.06-0.15(\nearrow)$ & $0.72-0.82(\searrow)$ \\
enclosed below & $0.27-0.33(\nearrow)$ & $0.28-0.31(\nearrow)$ & $0.37-0.44(\searrow)$ \\
ending above & $0.07-0.14(\nearrow)$ & $0.25-0.34(\rightarrow)$ & $0.58-0.66(\searrow)$ \\
ending below & $0.18-0.22(\nearrow)$ & $0.51-0.57(\searrow)$ & $0.22-0.29(\rightarrow)$ \\
isolated above & $0.20-0.34(\rightarrow)$ & $0.18-0.30(\rightarrow)$ & $0.45-0.54(\rightarrow)$ \\
isolated below & $0.32-0.44(\rightarrow)$ & $0.37-0.46(\rightarrow)$ & $0.15-0.22(\rightarrow)$ \\
\hline
\end{tabular}


Table 5: Parameters $a_{0}$ and $H$ describing the scale dependence of the parameter $a$ used in the $\mathrm{x} /(1-\mathrm{x})$-splitting and number of values for aggregation to $32 \mathrm{~h}\left(n_{32 h}\right)$ for the stations Cottbus (Cb), Köln-Bonn (Kö), Lindenberg (Li), Meiningen (Me), München-Flughafen (Mü) and Rostock-Warnemünde (Ro). Significance level of the relationships according to the t-test: $\mathrm{p} \leq 0.001^{* * *}, \mathrm{p} \leq 0.01 * *, \mathrm{p} \leq 0.05^{*}$

\begin{tabular}{|c|c|c|c|c|c|c|c|}
\hline $\begin{array}{l}\text { Position and } \\
\text { volume class }\end{array}$ & Parameter & $\mathrm{Cb}$ & Kö & $\mathrm{Li}$ & $\mathrm{Me}$ & Mü & Ro \\
\hline \multirow{3}{*}{ starting above } & $a_{0}$ & 1.3 & 1.1 & 1.2 & 1.2 & 0.9 & 1.2 \\
\hline & $H$ & $0.2 * * *$ & 0.2 & $0.2 *$ & 0.1 & 0.02 & $0.2^{* *}$ \\
\hline & $n_{32 h}$ & 114 & 139 & 114 & 122 & 116 & 135 \\
\hline \multirow{3}{*}{ starting below } & $a_{0}$ & 2.8 & 2.4 & 2.8 & 2.4 & 2.6 & 2.5 \\
\hline & $H$ & $0.3 *$ & $0.3 * *$ & $0.3^{* *}$ & $0.3 *$ & $0.4 *$ & $0.3^{* *}$ \\
\hline & $n_{32 h}$ & 94 & 143 & 115 & 115 & 132 & 114 \\
\hline \multirow{3}{*}{ enclosed above } & $a_{0}$ & 2.8 & 2.9 & 3.3 & 2.7 & 3.8 & 2.9 \\
\hline & $H$ & $0.4^{*}$ & $0.4^{* *}$ & $0.5 * * *$ & $0.4^{* *}$ & $0.5 * * *$ & $0.4^{* *}$ \\
\hline & $n_{32 h}$ & 322 & 489 & 294 & 437 & 327 & 329 \\
\hline \multirow{3}{*}{ enclosed below } & $a_{0}$ & 3.3 & 2.7 & 2.9 & 3.3 & 3.2 & 2.6 \\
\hline & $H$ & $0.4^{* *}$ & $0.4^{* *}$ & $0.3 *$ & $0.4^{* *}$ & 0.4 & $0.3^{* *}$ \\
\hline & $n_{32 h}$ & 333 & 447 & 301 & 448 & 346 & 341 \\
\hline \multirow{3}{*}{ ending above } & $a_{0}$ & 1.0 & 0.9 & 1.0 & 1.0 & 1.0 & 1.0 \\
\hline & $H$ & $0.2 *$ & $0.1 * *$ & 0.2 & $0.2 * *$ & 0.1 & $0.2 *$ \\
\hline & $n_{32 h}$ & 124 & 130 & 122 & 121 & 118 & 126 \\
\hline \multirow{3}{*}{ ending below } & $a_{0}$ & 3.4 & 2.9 & 3.3 & 3.5 & 3.4 & 3.4 \\
\hline & $H$ & $0.4^{* *}$ & $0.3 * *$ & $0.4^{* *}$ & $0.3 * * *$ & $0.4^{* *}$ & $0.4^{* *}$ \\
\hline & $n_{32 h}$ & 109 & 105 & 108 & 123 & 104 & 124 \\
\hline \multirow{3}{*}{ isolated above } & $a_{0}$ & 0.8 & 0.6 & 1.0 & 1.0 & 1.0 & 1.0 \\
\hline & $H$ & 0.1 & -0.2 & $0.2 *$ & 0.1 & $0.1 * * *$ & 0.1 \\
\hline & $n_{32 h}$ & 52 & 35 & 50 & 41 & 50 & 49 \\
\hline \multirow{3}{*}{ isolated below } & $a_{0}$ & 4.9 & 3.5 & 4.3 & 4.7 & 5.1 & 3.9 \\
\hline & $H$ & $0.5 * *$ & $0.4^{* *}$ & $0.4^{* *}$ & $0.5 *$ & $0.5 * *$ & 0.4 \\
\hline & $n_{32 h}$ & 48 & 27 & 50 & 45 & 51 & 37 \\
\hline
\end{tabular}


Table 6: Evaluation of the different cascade approaches at the example of the Lindenberg weather station

\begin{tabular}{|c|c|c|c|c|}
\hline Criterion & Data & C1 & $\mathrm{C} 2$ & C3 \\
\hline \multicolumn{5}{|c|}{ Intensity-frequency relationship (entire time series) } \\
\hline Dry ratio $(\%)$ & 91.0 & 94.4 & 80.5 & 90.5 \\
\hline Fraction of intervals $>0 \mathrm{~mm} / \mathrm{h}$ and $\leq 0.1 \mathrm{~mm} / \mathrm{h}(\%)$ & 2.5 & 1.2 & 10.7 & 3.1 \\
\hline $\begin{array}{l}\text { Fraction of intervals }>0.1 \mathrm{~mm} / \mathrm{h} \text { and } \leq 10 \mathrm{~mm} / \mathrm{h} \\
(\%)\end{array}$ & 6.5 & 4.4 & 8.8 & 6.3 \\
\hline Fraction of intervals $>10 \mathrm{~mm} / \mathrm{h}(\%)$ & 0.02 & 0.06 & 0.01 & 0.03 \\
\hline Mean intensity of wet intervals $(\mathrm{mm} / \mathrm{h})$ & 0.70 & 1.12 & 0.32 & 0.67 \\
\hline $\begin{array}{l}\text { Standard deviation of the intensity of wet intervals } \\
(\mathrm{mm} / \mathrm{h})\end{array}$ & 1.24 & 2.21 & 0.80 & 1.38 \\
\hline Skewness of the intensity of wet intervals & 8.87 & 7.05 & 9.19 & 8.27 \\
\hline Median intensity of wet intervals $(\mathrm{mm} / \mathrm{h})$ & 0.30 & 0.46 & 0.08 & 0.24 \\
\hline \multicolumn{5}{|c|}{ Temporal pattern (entire time series) } \\
\hline Mean dry spell duration (h) & 27.6 & 56.6 & 71.4 & 33.1 \\
\hline Standard deviation of the dry spell duration $(\mathrm{h})$ & 52.8 & 65.9 & 72.6 & 56.6 \\
\hline Skewness of the dry spell duration & 4.3 & 2.9 & 3.0 & 3.9 \\
\hline Mean wet spell duration $(\mathrm{h})$ & 2.7 & 3.3 & 17.3 & 3.4 \\
\hline Standard deviation of the wet spell duration $(\mathrm{h})$ & 2.8 & 2.8 & 21.2 & 2.8 \\
\hline Skewness of the wet spell duration (h) & 3.3 & 2.2 & 2.1 & 2.3 \\
\hline Spearman's rank autocorrelation, lag $1 \mathrm{~h}$ & 0.61 & 0.69 & 0.92 & 0.69 \\
\hline Spearman's rank autocorrelation, lag $3 \mathrm{~h}$ & 0.36 & 0.37 & 0.80 & 0.39 \\
\hline Spearman's rank autocorrelation, lag $6 \mathrm{~h}$ & 0.22 & 0.20 & 0.66 & 0.24 \\
\hline Spearman's rank autocorrelation, lag $9 \mathrm{~h}$ & 0.16 & 0.11 & 0.54 & 0.16 \\
\hline Pearson's autocorrelation, lag $1 \mathrm{~h}$ & 0.35 & 0.35 & 0.55 & 0.38 \\
\hline Pearson's autocorrelation, lag $3 \mathrm{~h}$ & 0.12 & 0.10 & 0.25 & 0.14 \\
\hline Pearson's autocorrelation, lag $6 \mathrm{~h}$ & 0.06 & 0.03 & 0.14 & 0.07 \\
\hline Pearson's autocorrelation, lag $9 \mathrm{~h}$ & 0.04 & 0.01 & 0.08 & 0.04 \\
\hline \multicolumn{5}{|l|}{ Event characteristics } \\
\hline Mean event dry ratio (\%) & 31.9 & 49.1 & 0.5 & 27.1 \\
\hline Standard deviation of the event dry ratio (\%) & 29.7 & 31.8 & 5.6 & 27.7 \\
\hline Skewness of the event dry ratio & 0.2 & -0.5 & 11.3 & 0.5 \\
\hline Median of the event dry ratio (\%) & 33.3 & 56.1 & 0.0 & 22.2 \\
\hline Partitioning $1^{\text {st }}$ quarter $(\%)$ & 34.7 & 22.5 & 25.2 & 30.5 \\
\hline Partitioning $2^{\text {nd }}$ quarter $(\%)$ & 20.5 & 27.9 & 24.7 & 19.8 \\
\hline Partitioning $3^{\text {rd }}$ quarter (\%) & 18.3 & 27.7 & 25.1 & 19.7 \\
\hline Partitioning $4^{\text {th }}$ quarter (\%) & 26.6 & 21.9 & 25.1 & 30.0 \\
\hline
\end{tabular}


Table 7: Evaluation of the general model performance of the coupled Poisson and cascade model at the example of the Lindenberg weather station

\begin{tabular}{|c|c|c|}
\hline Criterion & Data & $\begin{array}{l}\text { Coupled } \\
\text { Model }\end{array}$ \\
\hline \multicolumn{3}{|l|}{ Poisson Model Parameters } \\
\hline$d_{d, \text { mean }}(\mathrm{h})$ & 71.4 & 70.7 \\
\hline$d_{e, \text { mean }}(\mathrm{h})$ & 17.3 & 14.7 \\
\hline$i_{e, \text { mean }}(\mathrm{h})$ & 0.50 & 0.39 \\
\hline \multicolumn{3}{|l|}{ Poisson Model Result } \\
\hline Mean number of events & 1975 & 1968 \\
\hline \multicolumn{3}{|c|}{ Intensity-frequency relationship (entire time series) } \\
\hline Dry ratio $(\%)$ & 91.0 & 88.8 \\
\hline Fraction of intervals $>0 \mathrm{~mm} / \mathrm{h}$ and $\leq 0.1 \mathrm{~mm} / \mathrm{h}(\%)$ & 2.5 & 4.8 \\
\hline Fraction of intervals $>0.1 \mathrm{~mm} / \mathrm{h}$ and $\leq 10 \mathrm{~mm} / \mathrm{h}(\%)$ & 6.5 & 6.4 \\
\hline Fraction of intervals $>10 \mathrm{~mm} / \mathrm{h}(\%)$ & 0.02 & 0.03 \\
\hline Mean intensity of wet intervals $(\mathrm{mm} / \mathrm{h})$ & 0.70 & 0.57 \\
\hline Standard deviation of the intensity of wet intervals $(\mathrm{mm} / \mathrm{h})$ & 1.24 & 1.23 \\
\hline Skewness of the intensity of wet intervals & 8.87 & 6.70 \\
\hline Median intensity of wet intervals $(\mathrm{mm} / \mathrm{h})$ & 0.30 & 0.16 \\
\hline \multicolumn{3}{|l|}{ Temporal pattern (entire time series) } \\
\hline Mean dry spell duration $(\mathrm{h})$ & 27.6 & 32.3 \\
\hline Standard deviation of the dry spell duration $(\mathrm{h})$ & 52.8 & 47.4 \\
\hline Skewness of the dry spell duration & 4.3 & 2.6 \\
\hline Mean wet spell duration (h) & 2.7 & 4.0 \\
\hline Standard deviation of the wet spell duration $(\mathrm{h})$ & 2.8 & 3.1 \\
\hline Skewness of the wet spell duration (h) & 3.3 & 2.1 \\
\hline Spearman's rank autocorrelation, lag $1 \mathrm{~h}$ & 0.61 & 0.73 \\
\hline Spearman's rank autocorrelation, lag $3 \mathrm{~h}$ & 0.36 & 0.41 \\
\hline Spearman's rank autocorrelation, lag $6 \mathrm{~h}$ & 0.22 & 0.24 \\
\hline Spearman's rank autocorrelation, lag $9 \mathrm{~h}$ & 0.16 & 0.15 \\
\hline Pearson's autocorrelation, lag $1 \mathrm{~h}$ & 0.35 & 0.32 \\
\hline Pearson's autocorrelation, lag $3 \mathrm{~h}$ & 0.12 & 0.14 \\
\hline Pearson's autocorrelation, lag $6 \mathrm{~h}$ & 0.06 & 0.06 \\
\hline Pearson's autocorrelation, lag $9 \mathrm{~h}$ & 0.04 & 0.03 \\
\hline
\end{tabular}


Table A.1: Intensity-frequency relationships (entire time series): fraction of intervals within certain intensity ranges of the data and the different cascade models

\begin{tabular}{|c|c|c|c|c|c|}
\hline Criterion & Station & Data & $\mathrm{C} 1$ & $\mathrm{C} 2$ & C3 \\
\hline \multirow{6}{*}{ Dry ratio (\%) } & Cottbus & 90.7 & 94.2 & 79.3 & 90.1 \\
\hline & Köln-Bonn & 88.4 & 92.5 & 74.5 & 87.6 \\
\hline & Lindenberg & 91.0 & 94.4 & 80.5 & 90.5 \\
\hline & Meiningen & 88.7 & 93.3 & 75.6 & 88.5 \\
\hline & München-Flughafen & 89.2 & 93.4 & 79.7 & 89.1 \\
\hline & Rostock-Warnemünde & 90.7 & 93.7 & 76.1 & 89.9 \\
\hline \multirow{6}{*}{$\begin{array}{l}\text { Fraction of intervals } \\
>0 \mathrm{~mm} / \mathrm{h} \text { and } \leq 0.1 \\
\mathrm{~mm} / \mathrm{h}(\%)\end{array}$} & Cottbus & 2.6 & 1.2 & 11.5 & 3.1 \\
\hline & Köln-Bonn & 2.9 & 1.4 & 12.8 & 3.6 \\
\hline & Lindenberg & 2.5 & 1.2 & 10.7 & 3.1 \\
\hline & Meiningen & 3.2 & 1.4 & 13.6 & 3.7 \\
\hline & München-Flughafen & 2.6 & 1.3 & 9.8 & 3.3 \\
\hline & Rostock-Warnemünde & 2.5 & 1.4 & 14.0 & 3.3 \\
\hline \multirow{6}{*}{$\begin{array}{l}\text { Fraction of intervals } \\
>0.1 \mathrm{~mm} / \mathrm{h} \text { and } \leq 10 \\
\mathrm{~mm} / \mathrm{h}(\%)\end{array}$} & Cottbus & 6.6 & 4.5 & 9.1 & 6.5 \\
\hline & Köln-Bonn & 8.6 & 6.0 & 12.6 & 8.7 \\
\hline & Lindenberg & 6.5 & 4.4 & 8.8 & 6.3 \\
\hline & Meiningen & 7.9 & 5.1 & 10.7 & 7.6 \\
\hline & München-Flughafen & 8.0 & 5.2 & 10.5 & 7.6 \\
\hline & Rostock-Warnemünde & 6.8 & 4.9 & 9.9 & 6.8 \\
\hline \multirow{6}{*}{$\begin{array}{l}\text { Fraction of intervals } \\
>10 \mathrm{~mm} / \mathrm{h}(\%)\end{array}$} & Cottbus & 0.03 & 0.06 & 0.02 & 0.03 \\
\hline & Köln-Bonn & 0.04 & 0.09 & 0.02 & 0.04 \\
\hline & Lindenberg & 0.02 & 0.06 & 0.01 & 0.03 \\
\hline & Meiningen & 0.02 & 0.07 & 0.01 & 0.03 \\
\hline & München-Flughafen & 0.04 & 0.10 & 0.03 & 0.05 \\
\hline & Rostock-Warnemünde & 0.03 & 0.06 & 0.01 & 0.04 \\
\hline
\end{tabular}


Table A.2: Intensity-frequency relationships (entire time series): intensity of wet intervals of the data and the different cascade models

\begin{tabular}{llllll}
\hline Criterion & Station & Data & C1 & C2 & C3 \\
\hline & Cottbus & 0.69 & 1.11 & 0.31 & 0.65 \\
Mean intensity of wet & Köln-Bonn & 0.79 & 1.22 & 0.36 & 0.74 \\
intervals (mm/h) & Meiningen & 0.70 & 1.12 & 0.32 & 0.67 \\
& München-Flughafen & 0.80 & 1.30 & 0.42 & 0.78 \\
& Rostock-Warnemünde & 0.76 & 1.11 & 0.29 & 0.70 \\
\hline \multirow{3}{*}{ Standard deviation of } & Cottbus & 1.28 & 2.20 & 0.79 & 1.36 \\
the intensity of wet & Köln-Bonn & 1.37 & 2.27 & 0.81 & 1.41 \\
intervals (mm/h) & Meindenberg & 1.24 & 2.21 & 0.80 & 1.38 \\
& München-Flughafen & 1.44 & 2.50 & 0.97 & 1.54 \\
& Rostock-Warnemünde & 1.29 & 2.19 & 0.75 & 1.45 \\
\hline \multirow{3}{*}{ Skewness of the } & Cottbus & 9.00 & 7.45 & 10.50 & 8.64 \\
intensity of wet & Köln-Bonn & 7.80 & 6.83 & 7.67 & 7.45 \\
& Lindenberg & 8.87 & 7.05 & 9.19 & 8.27 \\
& Meiningen & 10.20 & 6.24 & 9.05 & 7.40 \\
& München-Flughafen & 8.32 & 6.28 & 7.58 & 7.00 \\
& Rostock-Warnemünde & 6.0 & 8.26 & 9.13 & 9.53 \\
\hline \multirow{2}{*}{ Median intensity of } & Cottbus & 0.30 & 0.44 & 0.08 & 0.24 \\
wet intervals (mm/h) & Köln-Bonn & 0.40 & 0.52 & 0.10 & 0.30 \\
& Lindenberg & 0.30 & 0.46 & 0.08 & 0.24 \\
& Meiningen & 0.30 & 0.45 & 0.07 & 0.25 \\
& München-Flughafen & 0.40 & 0.53 & 0.11 & 0.29 \\
& Rostock-Warnemünde & 0.40 & 0.46 & 0.06 & 0.26 \\
\hline
\end{tabular}


Table A.3: Temporal pattern (entire time series): dry and wet spell durations of the data and the different cascade models

\begin{tabular}{|c|c|c|c|c|c|}
\hline Criterion & Station & Data & $\mathrm{C} 1$ & $\mathrm{C} 2$ & C3 \\
\hline \multirow{6}{*}{$\begin{array}{l}\text { Mean dry spell } \\
\text { duration }(\mathrm{h})\end{array}$} & Cottbus & 26.6 & 56.4 & 71.1 & 32.2 \\
\hline & Köln-Bonn & 21.3 & 47.2 & 62.8 & 26.2 \\
\hline & Lindenberg & 27.6 & 56.6 & 71.4 & 33.1 \\
\hline & Meiningen & 21.8 & 51.4 & 66.8 & 28.1 \\
\hline & München-Flughafen & 25.0 & 51.7 & 65.3 & 30.5 \\
\hline & Rostock-Warnemünde & 25.7 & 53.5 & 74.7 & 30.9 \\
\hline \multirow{6}{*}{$\begin{array}{l}\text { Standard deviation of } \\
\text { the dry spell duration } \\
\text { (h) }\end{array}$} & Cottbus & 51.7 & 70.0 & 72.2 & 55.9 \\
\hline & Köln-Bonn & 43.2 & 61.5 & 63.8 & 47.1 \\
\hline & Lindenberg & 52.8 & 65.9 & 72.6 & 56.6 \\
\hline & Meiningen & 44.9 & 64.7 & 66.5 & 49.8 \\
\hline & München-Flughafen & 48.1 & 63.5 & 65.4 & 51.9 \\
\hline & Rostock-Warnemünde & 50.8 & 70.3 & 74.1 & 54.9 \\
\hline \multirow{6}{*}{$\begin{array}{l}\text { Skewness of the dry } \\
\text { spell duration }\end{array}$} & Cottbus & 4.4 & 2.9 & 3.0 & 4.1 \\
\hline & Köln-Bonn & 4.9 & 3.0 & 3.1 & 4.4 \\
\hline & Lindenberg & 4.3 & 2.9 & 3.0 & 3.9 \\
\hline & Meiningen & 4.5 & 2.6 & 2.7 & 3.9 \\
\hline & München-Flughafen & 4.3 & 2.8 & 3.0 & 3.9 \\
\hline & Rostock-Warnemünde & 4.7 & 2.9 & 3.0 & 4.2 \\
\hline \multirow{6}{*}{$\begin{array}{l}\text { Mean wet spell } \\
\text { duration }(\mathrm{h})\end{array}$} & Cottbus & 2.7 & 3.5 & 18.5 & 3.5 \\
\hline & Köln-Bonn & 2.7 & 3.8 & 21.4 & 4.0 \\
\hline & Lindenberg & 2.7 & 3.3 & 17.3 & 3.4 \\
\hline & Meiningen & 2.7 & 3.7 & 21.6 & 3.6 \\
\hline & München-Flughafen & 3.0 & 3.6 & 16.7 & 3.7 \\
\hline & Rostock-Warnemünde & 2.6 & 3.6 & 23.6 & 3.5 \\
\hline \multirow{6}{*}{$\begin{array}{l}\text { Standard deviation of } \\
\text { the wet spell duration } \\
\text { (h) }\end{array}$} & Cottbus & 2.9 & 2.9 & 23.1 & 3.0 \\
\hline & Köln-Bonn & 2.9 & 3.2 & 26.6 & 3.1 \\
\hline & Lindenberg & 2.8 & 2.8 & 21.2 & 2.8 \\
\hline & Meiningen & 2.9 & 3.1 & 27.1 & 3.1 \\
\hline & München-Flughafen & 3.5 & 3.2 & 20.0 & 3.3 \\
\hline & Rostock-Warnemünde & 2.6 & 3.0 & 29.2 & 2.9 \\
\hline \multirow{6}{*}{$\begin{array}{l}\text { Skewness of the wet } \\
\text { spell duration }(\mathrm{h})\end{array}$} & Cottbus & 3.8 & 2.3 & 2.4 & 2.3 \\
\hline & Köln-Bonn & 3.1 & 2.1 & 3.0 & 3.0 \\
\hline & Lindenberg & 3.3 & 2.2 & 2.1 & 2.3 \\
\hline & Meiningen & 3.3 & 2.1 & 2.5 & 2.3 \\
\hline & München-Flughafen & 3.9 & 2.3 & 2.3 & 2.3 \\
\hline & Rostock-Warnemünde & 3.4 & 2.2 & 2.3 & 2.2 \\
\hline
\end{tabular}


Table A.4: Temporal pattern (entire time series): autocorrelation functions of the data and the different cascade models

\begin{tabular}{|c|c|c|c|c|c|c|c|c|c|}
\hline \multirow{2}{*}{$\begin{array}{l}\text { Lag time } \\
\text { (h) }\end{array}$} & \multirow{2}{*}{ Station } & \multicolumn{4}{|c|}{ Spearman } & \multicolumn{4}{|c|}{ Pearson } \\
\hline & & Data & $\mathrm{C} 1$ & $\mathrm{C} 2$ & C3 & Data & $\mathrm{C} 1$ & $\mathrm{C} 2$ & C3 \\
\hline \multirow{6}{*}{1} & Cottbus & 0.61 & 0.69 & 0.92 & 0.68 & 0.38 & 0.40 & 0.53 & 0.42 \\
\hline & Köln-Bonn & 0.61 & 0.72 & 0.93 & 0.70 & 0.36 & 0.37 & 0.60 & 0.42 \\
\hline & Lindenberg & 0.61 & 0.69 & 0.92 & 0.69 & 0.35 & 0.35 & 0.55 & 0.38 \\
\hline & Meiningen & 0.61 & 0.72 & 0.93 & 0.70 & 0.39 & 0.42 & 0.56 & 0.42 \\
\hline & München-Flughafen & 0.65 & 0.71 & 0.92 & 0.70 & 0.36 & 0.37 & 0.54 & 0.42 \\
\hline & Rostock-Warnemünde & 0.60 & 0.71 & 0.94 & 0.68 & 0.41 & 0.42 & 0.57 & 0.45 \\
\hline \multirow{6}{*}{3} & Cottbus & 0.37 & 0.38 & 0.81 & 0.39 & 0.13 & 0.10 & 0.22 & 0.14 \\
\hline & Köln-Bonn & 0.37 & 0.41 & 0.81 & 0.40 & 0.14 & 0.10 & 0.26 & 0.14 \\
\hline & Lindenberg & 0.36 & 0.37 & 0.80 & 0.39 & 0.12 & 0.10 & 0.25 & 0.14 \\
\hline & Meiningen & 0.39 & 0.41 & 0.82 & 0.42 & 0.14 & 0.11 & 0.24 & 0.14 \\
\hline & München-Flughafen & 0.42 & 0.41 & 0.79 & 0.43 & 0.15 & 0.11 & 0.27 & 0.16 \\
\hline & Rostock-Warnemünde & 0.34 & 0.40 & 0.84 & 0.38 & 0.14 & 0.11 & 0.25 & 0.14 \\
\hline \multirow{6}{*}{6} & Cottbus & 0.23 & 0.21 & 0.67 & 0.22 & 0.06 & 0.03 & 0.14 & 0.07 \\
\hline & Köln-Bonn & 0.22 & 0.24 & 0.67 & 0.24 & 0.07 & 0.04 & 0.15 & 0.06 \\
\hline & Lindenberg & 0.22 & 0.20 & 0.66 & 0.24 & 0.06 & 0.03 & 0.14 & 0.07 \\
\hline & Meiningen & 0.25 & 0.23 & 0.68 & 0.26 & 0.06 & 0.03 & 0.13 & 0.07 \\
\hline & München-Flughafen & 0.28 & 0.22 & 0.64 & 0.28 & 0.08 & 0.04 & 0.13 & 0.08 \\
\hline & Rostock-Warnemünde & 0.19 & 0.23 & 0.70 & 0.22 & 0.09 & 0.05 & 0.13 & 0.07 \\
\hline \multirow{6}{*}{9} & Cottbus & 0.16 & 0.12 & 0.55 & 0.14 & 0.04 & 0.02 & 0.08 & 0.03 \\
\hline & Köln-Bonn & 0.15 & 0.15 & 0.55 & 0.16 & 0.04 & 0.03 & 0.10 & 0.05 \\
\hline & Lindenberg & 0.16 & 0.11 & 0.54 & 0.16 & 0.04 & 0.01 & 0.08 & 0.04 \\
\hline & Meiningen & 0.18 & 0.14 & 0.57 & 0.17 & 0.04 & 0.02 & 0.09 & 0.04 \\
\hline & München-Flughafen & 0.20 & 0.13 & 0.51 & 0.18 & 0.06 & 0.02 & 0.08 & 0.05 \\
\hline & Rostock-Warnemünde & 0.12 & 0.15 & 0.60 & 0.15 & 0.04 & 0.03 & 0.09 & 0.06 \\
\hline
\end{tabular}


Table A.5: Event characteristics: event dry ratio of the data and the different cascade $\underline{\text { models }}$

\begin{tabular}{llllll}
\hline Criterion & Station & Data & C1 & C2 & C3 \\
\hline & Cottbus & 32.9 & 49.8 & 0.5 & 27.8 \\
& Köln-Bonn & 34.7 & 51.3 & 0.6 & 29.6 \\
Mean event dry ratio & Lindenberg & 31.9 & 49.1 & 0.5 & 27.1 \\
& Meiningen & 34.9 & 51.8 & 0.6 & 29.9 \\
& München-Flughafen & 29.3 & 48.1 & 0.5 & 25.1 \\
& Rostock-Warnemünde & 38.8 & 53.5 & 0.6 & 33.1 \\
\hline \multirow{5}{*}{ Standard deviation of } & Cottbus & 30.3 & 31.8 & 5.7 & 27.9 \\
the event dry ratio (\%) & Köln-Bonn & 29.0 & 30.3 & 5.8 & 26.8 \\
& Lindenberg & 29.7 & 31.8 & 5.6 & 27.7 \\
& Meiningen & 28.6 & 31.3 & 5.8 & 27.5 \\
& München-Flughafen & 27.8 & 30.9 & 5.2 & 25.7 \\
& Rostock-Warnemünde & 31.0 & 30.7 & 6.3 & 28.9 \\
\hline \multirow{5}{*}{ Skewness of the event } & Cottbus & 0.2 & -0.5 & 11.2 & 0.4 \\
& Köln-Bonn & 0.0 & -0.5 & 10.7 & 0.3 \\
& Lindenberg & 0.2 & -0.5 & 11.3 & 0.5 \\
& Meiningen & -0.1 & -0.6 & 10.6 & 0.3 \\
& München-Flughafen & 0.3 & -0.4 & 11.5 & 0.5 \\
& Rostock-Warnemünde & -0.1 & -0.7 & 10.4 & 0.1 \\
\hline \multirow{5}{*}{ Median of the event dry } & Cottbus & 33.3 & 57.1 & 0.0 & 24.0 \\
ratio (\%) & Köln-Bonn & 37.9 & 58.9 & 0.0 & 28.6 \\
& Lindenberg & 33.3 & 56.1 & 0.0 & 22.2 \\
& Meiningen & 39.8 & 60.0 & 0.0 & 28.6 \\
& München-Flughafen & 27.5 & 53.3 & 0.0 & 20.0 \\
& Rostock-Warnemünde & 44.4 & 62.1 & 0.0 & 33.3 \\
\hline
\end{tabular}


Table A.6: Event characteristics: precipitation partitioning within events of the data and the different cascade models

\begin{tabular}{|c|c|c|c|c|c|}
\hline Station & Quarter & Data & C1 & $\mathrm{C} 2$ & C3 \\
\hline \multirow{4}{*}{$\begin{array}{l}\text { Cottbus }(\%) \\
\text { (based on } 368 \text { events) }\end{array}$} & 1 & 34.6 & 22.9 & 25.2 & 30.2 \\
\hline & 2 & 20.5 & 28.2 & 25.0 & 19.5 \\
\hline & 3 & 19.0 & 27.5 & 24.8 & 20.3 \\
\hline & 4 & 25.9 & 21.5 & 25.0 & 30.0 \\
\hline \multirow{4}{*}{$\begin{array}{l}\text { Köln-Bonn }(\%) \\
\text { (based on } 418 \text { events) }\end{array}$} & 1 & 34.5 & 19.7 & 25.3 & 29.7 \\
\hline & 2 & 21.8 & 26.4 & 25.0 & 20.0 \\
\hline & 3 & 18.9 & 29.3 & 25.0 & 20.3 \\
\hline & 4 & 35.2 & 24.6 & 24.7 & 30.0 \\
\hline \multirow{4}{*}{$\begin{array}{l}\text { Lindenberg (\%) } \\
\text { (based on } 396 \text { events) }\end{array}$} & 1 & 34.7 & 22.5 & 25.2 & 30.5 \\
\hline & 2 & 20.5 & 27.9 & 24.7 & 19.8 \\
\hline & 3 & 18.3 & 27.7 & 25.1 & 19.7 \\
\hline & 4 & 26.6 & 21.9 & 25.1 & 30.0 \\
\hline \multirow{4}{*}{$\begin{array}{l}\text { Meiningen }(\%) \\
\text { (based on } 408 \text { events) }\end{array}$} & 1 & 31.8 & 23.5 & 24.9 & 30.0 \\
\hline & 2 & 20.5 & 28.0 & 25.0 & 19.8 \\
\hline & 3 & 19.3 & 27.1 & 25.1 & 20.0 \\
\hline & 4 & 28.3 & 21.5 & 25.0 & 30.1 \\
\hline \multirow{4}{*}{$\begin{array}{l}\text { München-Flughafen (\%) } \\
\text { (based on } 419 \text { events) }\end{array}$} & 1 & 33.5 & 21.8 & 24.8 & 29.9 \\
\hline & 2 & 18.9 & 28.3 & 25.2 & 19.9 \\
\hline & 3 & 20.3 & 27.9 & 25.0 & 20.2 \\
\hline & 4 & 27.2 & 21.9 & 25.0 & 30.0 \\
\hline \multirow{4}{*}{$\begin{array}{l}\text { Rostock-Warnemünde (\%) } \\
\text { (based on } 378 \text { events) }\end{array}$} & 1 & 31.9 & 23.2 & 25.2 & 30.3 \\
\hline & 2 & 18.2 & 28.4 & 25.5 & 19.7 \\
\hline & 3 & 19.9 & 27.0 & 24.8 & 19.6 \\
\hline & 4 & 29.9 & 21.4 & 24.5 & 30.4 \\
\hline
\end{tabular}


Table A.7: Parameters of the Poisson rectangular pulse model recalculated from generated time series: Mean of the dry period durations $d_{d, \text { mean }}$, mean event duration $d_{e, \text { mean }}$, mean event intensity $i_{e, \text { mean }}$

\begin{tabular}{llll}
\hline Station & $d_{d, \text { mean }}(\mathrm{h})$ & $d_{e, \text { mean }}(\mathrm{h})$ & $i_{e, \text { mean }}(\mathrm{mm} / \mathrm{h})$ \\
\hline Cottbus & 70.3 & 19.6 & 0.33 \\
Köln-Bonn & 62.1 & 22.4 & 0.36 \\
Lindenberg & 70.7 & 14.7 & 0.39 \\
Meiningen & 66.1 & 22.6 & 0.32 \\
München-Flughafen & 64.6 & 17.6 & 0.41 \\
Rostock-Warnemünde & 73.9 & 24.6 & 0.34 \\
\hline
\end{tabular}

Table A.8: Number of events in the observed data and generated events (average of 60 realisations)

\begin{tabular}{lll} 
Station & Data & Coupled Model \\
\hline Cottbus & 1956 & 1950 \\
Köln-Bonn & 2079 & 2073 \\
Lindenberg & 1975 & 1968 \\
Meiningen & 1976 & 1975 \\
München-Flughafen & 2136 & 2132 \\
Rostock-Warnemünde & 1776 & 1779 \\
\hline
\end{tabular}


Table A.9: Intensity-frequency relationships (entire time series): fraction of intervals within certain intensity ranges of the data and the coupled Poisson and cascade model

\begin{tabular}{|c|c|c|c|}
\hline Criterion & Station & Data & Coupled Model \\
\hline \multirow{6}{*}{ Dry ratio (\%) } & Cottbus & 90.7 & 88.1 \\
\hline & Köln-Bonn & 88.4 & 85.5 \\
\hline & Lindenberg & 91.0 & 88.8 \\
\hline & Meiningen & 88.7 & 86.2 \\
\hline & München-Flughafen & 89.3 & 87.0 \\
\hline & Rostock-Warnemünde & 90.7 & 88.0 \\
\hline \multirow{6}{*}{$\begin{array}{l}\text { Fraction of intervals } \\
>0 \mathrm{~mm} / \mathrm{h} \text { and } \leq 0.1 \\
\mathrm{~mm} / \mathrm{h}(\%)\end{array}$} & Cottbus & 2.6 & 5.1 \\
\hline & Köln-Bonn & 2.9 & 5.5 \\
\hline & Lindenberg & 2.5 & 4.8 \\
\hline & Meiningen & 3.3 & 5.6 \\
\hline & München-Flughafen & 2.6 & 5.1 \\
\hline & Rostock-Warnemünde & 2.5 & 4.9 \\
\hline \multirow{6}{*}{$\begin{array}{l}\text { Fraction of intervals } \\
>0.1 \mathrm{~mm} / \mathrm{h} \text { and } \leq 10 \\
\mathrm{~mm} / \mathrm{h}(\%)\end{array}$} & Cottbus & 6.6 & 6.8 \\
\hline & Köln-Bonn & 8.6 & 9.0 \\
\hline & Lindenberg & 6.5 & 6.4 \\
\hline & Meiningen & 7.9 & 8.1 \\
\hline & München-Flughafen & 8.0 & 7.8 \\
\hline & Rostock-Warnemünde & 6.8 & 7.0 \\
\hline \multirow{6}{*}{$\begin{array}{l}\text { Fraction of intervals } \\
>10 \mathrm{~mm} / \mathrm{h}(\%)\end{array}$} & Cottbus & 0.03 & 0.03 \\
\hline & Köln-Bonn & 0.04 & 0.05 \\
\hline & Lindenberg & 0.02 & 0.03 \\
\hline & Meiningen & 0.02 & 0.03 \\
\hline & München-Flughafen & 0.04 & 0.05 \\
\hline & Rostock-Warnemünde & 0.03 & 0.03 \\
\hline
\end{tabular}


Table A.10: Intensity-frequency relationships (entire time series): intensities of wet intervals of the data and the coupled Poisson and cascade model

\begin{tabular}{llll}
\hline Criterion & Station & Data & Coupled Model \\
\hline & Cottbus & 0.69 & 0.56 \\
Mean intensity of wet & Köln-Bonn & 0.79 & 0.66 \\
intervals (mm/h) & Meiningen & 0.70 & 0.57 \\
& München-Flughafen & 0.66 & 0.57 \\
& Rostock-Warnemünde & 0.80 & 0.69 \\
\hline \multirow{3}{*}{ Standard deviation of } & Cottbus & 0.76 & 0.60 \\
the intensity of wet & Löln-Bonn & 1.28 & 1.25 \\
intervals (mm/h) & Meiningen & 1.37 & 1.39 \\
& München-Flughafen & 1.24 & 1.23 \\
& Rostock-Warnemünde & 1.16 & 1.22 \\
Skewness of the & Cottbus & 9.00 & 1.49 \\
intensity of wet & Köln-Bonn & 7.80 & 1.29 \\
intervals & Lindenberg & 8.87 & 7.33 \\
& Meiningen & 10.20 & 7.52 \\
& München-Flughafen & 8.32 & 7.32 \\
& Rostock-Warnemünde & 6.0 & 7.08 \\
\hline \multirow{2}{*}{ Median intensity of } & Lindenberg & 0.30 & 0.15 \\
wet intervals (mm/h) & Meiningen & 0.40 & 0.20 \\
& München-Flughafen & 0.30 & 0.16 \\
& Rostock-Warnemünde & 0.40 & 0.17 \\
\hline
\end{tabular}


Table A.11: Intensity-frequency relationships (entire time series): hourly extreme precipitation values based on the observations and median values of 60 realisations of the coupled model

\begin{tabular}{|c|c|c|c|}
\hline Return period (a) & Station & Data & Coupled Model \\
\hline \multirow{6}{*}{0.5} & Cottbus & 10.6 & 11.1 \\
\hline & Köln-Bonn & 12.7 & 13.2 \\
\hline & Lindenberg & 10.3 & 10.6 \\
\hline & Meiningen & 9.9 & 11.6 \\
\hline & München-Flughafen & 13.6 & 13.4 \\
\hline & Rostock-Warnemünde & 11.1 & 11.6 \\
\hline \multirow{6}{*}{1.0} & Cottbus & 13.7 & 14.1 \\
\hline & Köln-Bonn & 17.4 & 16.1 \\
\hline & Lindenberg & 14.3 & 13.4 \\
\hline & Meiningen & 13.5 & 14.4 \\
\hline & München-Flughafen & 18.1 & 17.0 \\
\hline & Rostock-Warnemünde & 14.4 & 14.5 \\
\hline \multirow{6}{*}{2.0} & Cottbus & 18.7 & 17.4 \\
\hline & Köln-Bonn & 22.5 & 20.1 \\
\hline & Lindenberg & 18.9 & 16.4 \\
\hline & Meiningen & 15.8 & 17.9 \\
\hline & München-Flughafen & 24.4 & 20.6 \\
\hline & Rostock-Warnemünde & 16.9 & 17.6 \\
\hline \multirow{6}{*}{5.6} & Cottbus & 22.9 & 23.2 \\
\hline & Köln-Bonn & 24.4 & 25.5 \\
\hline & Lindenberg & 22.8 & 20.6 \\
\hline & Meiningen & 20.4 & 23.5 \\
\hline & München-Flughafen & 29.2 & 26.3 \\
\hline & Rostock-Warnemünde & 19.0 & 23.4 \\
\hline \multirow{6}{*}{12.6} & Cottbus & 27.0 & 27.1 \\
\hline & Köln-Bonn & 27.0 & 30.8 \\
\hline & Lindenberg & 31.1 & 24.0 \\
\hline & Meiningen & 28.4 & 27.3 \\
\hline & München-Flughafen & 32.2 & 32.9 \\
\hline & Rostock-Warnemünde & 21.4 & 28.2 \\
\hline
\end{tabular}


Table A.12: Intensity-frequency relationships (entire time series): daily extreme precipitation values based on the observation and median values of 60 realisations of the coupled model

\begin{tabular}{|c|c|c|c|}
\hline Return period (a) & Station & Data & Coupled Model \\
\hline \multirow{6}{*}{0.5} & Cottbus & 20.9 & 26.0 \\
\hline & Köln-Bonn & 25.3 & 31.8 \\
\hline & Lindenberg & 22.2 & 24.3 \\
\hline & Meiningen & 22.0 & 26.8 \\
\hline & München-Flughafen & 30.0 & 33.6 \\
\hline & Rostock-Warnemünde & 22.2 & 26.5 \\
\hline \multirow{6}{*}{1} & Cottbus & 30.8 & 32.1 \\
\hline & Köln-Bonn & 31.7 & 38.7 \\
\hline & Lindenberg & 29.1 & 29.5 \\
\hline & Meiningen & 26.0 & 32.4 \\
\hline & München-Flughafen & 34.0 & 41.4 \\
\hline & Rostock-Warnemünde & 28.5 & 32.6 \\
\hline \multirow{6}{*}{2} & Cottbus & 35.7 & 38.0 \\
\hline & Köln-Bonn & 38.4 & 46.1 \\
\hline & Lindenberg & 34.2 & 35.0 \\
\hline & Meiningen & 30.7 & 38.5 \\
\hline & München-Flughafen & 42.1 & 48.5 \\
\hline & Rostock-Warnemünde & 32.4 & 38.5 \\
\hline \multirow{6}{*}{5.6} & Cottbus & 52.7 & 46.2 \\
\hline & Köln-Bonn & 47.6 & 57.1 \\
\hline & Lindenberg & 41.6 & 42.9 \\
\hline & Meiningen & 41.8 & 48.0 \\
\hline & München-Flughafen & 52.2 & 60.3 \\
\hline & Rostock-Warnemünde & 44.8 & 46.0 \\
\hline \multirow{6}{*}{12.6} & Cottbus & 59.7 & 53.5 \\
\hline & Köln-Bonn & 68.1 & 66.4 \\
\hline & Lindenberg & 49.3 & 48.3 \\
\hline & Meiningen & 55.9 & 54.4 \\
\hline & München-Flughafen & 55.9 & 68.3 \\
\hline & Rostock-Warnemünde & 92.2 & 53.8 \\
\hline
\end{tabular}


Table A.13: Temporal pattern (entire time series): dry and wet spell durations of the data and the coupled Poisson and cascade model

\begin{tabular}{|c|c|c|c|}
\hline Criterion & Station & Data & Coupled Model \\
\hline \multirow{6}{*}{$\begin{array}{l}\text { Mean dry spell duration } \\
\text { (h) }\end{array}$} & Cottbus & 26.6 & 31.5 \\
\hline & Köln-Bonn & 21.3 & 25.8 \\
\hline & Lindenberg & 27.6 & 32.3 \\
\hline & Meiningen & 21.8 & 27.5 \\
\hline & München-Flughafen & 25.0 & 30.6 \\
\hline & Rostock-Warnemünde & 25.7 & 30.3 \\
\hline \multirow{6}{*}{$\begin{array}{l}\text { Standard deviation of } \\
\text { the dry spell duration } \\
\text { (h) }\end{array}$} & Cottbus & 51.7 & 46.7 \\
\hline & Köln-Bonn & 43.2 & 39.3 \\
\hline & Lindenberg & 52.8 & 47.4 \\
\hline & Meiningen & 44.9 & 42.5 \\
\hline & München-Flughafen & 48.1 & 45.1 \\
\hline & Rostock-Warnemünde & 50.8 & 45.8 \\
\hline \multirow{6}{*}{$\begin{array}{l}\text { Skewness of the dry } \\
\text { spell duration }\end{array}$} & Cottbus & 4.4 & 2.6 \\
\hline & Köln-Bonn & 4.9 & 2.7 \\
\hline & Lindenberg & 4.3 & 2.6 \\
\hline & Meiningen & 4.5 & 2.8 \\
\hline & München-Flughafen & 4.3 & 2.6 \\
\hline & Rostock-Warnemünde & 4.7 & 2.7 \\
\hline \multirow{6}{*}{$\begin{array}{l}\text { Mean wet spell duration } \\
\text { (h) }\end{array}$} & Cottbus & 2.7 & 4.3 \\
\hline & Köln-Bonn & 2.7 & 4.4 \\
\hline & Lindenberg & 2.7 & 4.0 \\
\hline & Meiningen & 2.7 & 4.3 \\
\hline & München-Flughafen & 3.0 & 4.6 \\
\hline & Rostock-Warnemünde & 2.6 & 4.1 \\
\hline \multirow{6}{*}{$\begin{array}{l}\text { Standard deviation of } \\
\text { the wet spell duration } \\
\text { (h) }\end{array}$} & Cottbus & 2.9 & 3.3 \\
\hline & Köln-Bonn & 2.9 & 3.4 \\
\hline & Lindenberg & 2.8 & 3.1 \\
\hline & Meiningen & 2.9 & 3.5 \\
\hline & München-Flughafen & 3.5 & 3.6 \\
\hline & Rostock-Warnemünde & 2.6 & 3.1 \\
\hline \multirow{6}{*}{$\begin{array}{l}\text { Skewness of the wet } \\
\text { spell duration }(\mathrm{h})\end{array}$} & Cottbus & 3.8 & 2.1 \\
\hline & Köln-Bonn & 3.1 & 2.1 \\
\hline & Lindenberg & 3.3 & 2.1 \\
\hline & Meiningen & 3.3 & 2.1 \\
\hline & München-Flughafen & 3.9 & 2.1 \\
\hline & Rostock-Warnemünde & 3.4 & 2.1 \\
\hline
\end{tabular}


Table A.14: Temporal pattern (entire time series): autocorrelation functions of the data and the coupled Poisson and cascade model

\begin{tabular}{|c|c|c|c|c|c|}
\hline \multirow{2}{*}{$\begin{array}{l}\text { Lag } \\
\text { time }(\mathrm{h})\end{array}$} & \multirow{2}{*}{ Station } & \multicolumn{2}{|c|}{ Spearman } & \multicolumn{2}{|c|}{ Pearson } \\
\hline & & Data & Model & Data & Model \\
\hline \multirow{6}{*}{1} & Cottbus & 0.61 & 0.75 & 0.38 & 0.42 \\
\hline & Köln-Bonn & 0.61 & 0.74 & 0.36 & 0.44 \\
\hline & Lindenberg & 0.61 & 0.73 & 0.35 & 0.32 \\
\hline & Meiningen & 0.61 & 0.74 & 0.39 & 0.44 \\
\hline & München-Flughafen & 0.65 & 0.75 & 0.36 & 0.47 \\
\hline & Rostock-Warnemünde & 0.60 & 0.73 & 0.41 & 0.46 \\
\hline \multirow{6}{*}{3} & Cottbus & 0.37 & 0.44 & 0.13 & 0.16 \\
\hline & Köln-Bonn & 0.37 & 0.44 & 0.14 & 0.16 \\
\hline & Lindenberg & 0.36 & 0.41 & 0.12 & 0.14 \\
\hline & Meiningen & 0.39 & 0.46 & 0.14 & 0.14 \\
\hline & München-Flughafen & 0.42 & 0.46 & 0.15 & 0.18 \\
\hline & Rostock-Warnemünde & 0.34 & 0.43 & 0.14 & 0.15 \\
\hline \multirow{6}{*}{6} & Cottbus & 0.23 & 0.27 & 0.06 & 0.08 \\
\hline & Köln-Bonn & 0.22 & 0.27 & 0.07 & 0.09 \\
\hline & Lindenberg & 0.22 & 0.24 & 0.06 & 0.06 \\
\hline & Meiningen & 0.25 & 0.29 & 0.06 & 0.08 \\
\hline & München-Flughafen & 0.28 & 0.29 & 0.08 & 0.09 \\
\hline & Rostock-Warnemünde & 0.19 & 0.26 & 0.09 & 0.07 \\
\hline \multirow{6}{*}{9} & Cottbus & 0.16 & 0.18 & 0.04 & 0.05 \\
\hline & Köln-Bonn & 0.15 & 0.18 & 0.04 & 0.06 \\
\hline & Lindenberg & 0.16 & 0.15 & 0.04 & 0.03 \\
\hline & Meiningen & 0.18 & 0.19 & 0.04 & 0.06 \\
\hline & München-Flughafen & 0.20 & 0.19 & 0.06 & 0.05 \\
\hline & Rostock-Warnemünde & 0.12 & 0.16 & 0.04 & 0.04 \\
\hline
\end{tabular}

